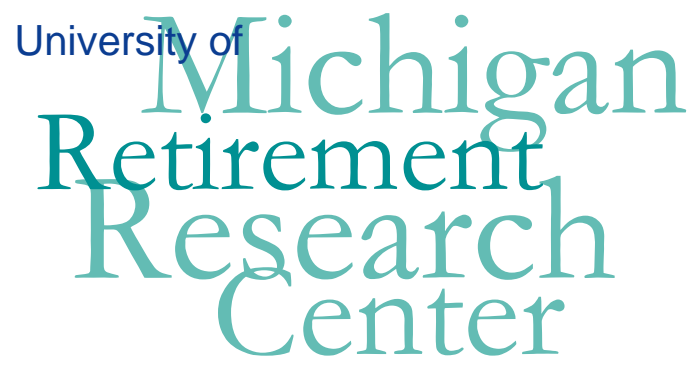

Working Paper

WP 2006-142

Consumption, Retirement, and Social Security: Evaluating the Efficiency of Reform with a Life-Cycle Model

John Laitner and Daniel Silverman

\begin{tabular}{|l|l|l|}
\hline $\mathrm{M}$ & $\mathrm{R}$ \\
\hline $\mathrm{R}$ & $\mathrm{C}$ & \\
\hline
\end{tabular}$\quad$ Project \#: UM05-19 


\title{
“Consumption, Retirement, and Social Security: Evaluating the Efficiency of Reform with a Life-cycle Model”
}

\author{
John Laitner \\ University of Michigan \\ Daniel Silverman \\ University of Michigan
}

November 2006

Michigan Retirement Research Center

University of Michigan

P.O. Box 1248

Ann Arbor, MI 48104

http://www.mrrc.isr.umich.edu/

(734) 615-0422

\section{Acknowledgements}

This work was supported by a grant from the Social Security Administration through the Michigan Retirement Research Center (Grant \# 10-P-98358-5). The findings and conclusions expressed are solely those of the author and do not represent the views of the Social Security Administration, any agency of the Federal government, or the Michigan Retirement Research Center.

Regents of the University of Michigan

David A. Brandon, Ann Arbor; Laurence B. Deitch, Bingham Farms; Olivia P. Maynard, Goodrich; Rebecca McGowan, Ann Arbor; Andrea Fischer Newman, Ann Arbor; Andrew C. Richner, Grosse Pointe Park; S. Martin Taylor, Gross Pointe Farms; Katherine E. White, Ann Arbor; Mary Sue Coleman, ex officio 


\title{
Consumption, Retirement, and Social Security: Evaluating the Efficiency of Reform with a Life-cycle Model
}

\author{
John Laitner and Daniel Silverman
}

\begin{abstract}
This paper analyzes the effect of a potential reform to the Social Security system on individuals' retirement and consumption choices. We first estimate the coefficients for a life-cycle model. We assume intratemporally nonseparable preference orderings and endogenous retirement. Our framework allows the possibility of disability. The specification predicts a change in consumption at retirement; we use the empirical magnitude of the change, together with desired retirement age, to identify key parameters such as the curvature of the utility function. We then qualitatively and quantitatively study the possible long-run effect of a Social Security reform in which individuals no longer face the OASI payroll tax after some specified age, and their subsequent earnings have no bearing on their Social Security benefits. Simulations indicate that retirement ages would rise by as much as one year, equivalent variations could average \$5000 (1984 dollars) per household or more, and reform could generate $\$ 2500$ or more additional income tax revenue per household.
\end{abstract}

\section{Authors' Acknowledgements}

Osamu Aruga and Lina Walker provided excellent research assistance with the CEX and HRS data sets, respectively. We are grateful to David Blau, John Bound, Miles Kimball, Jeff Liebman, Richard Rogerson, Matthew Shapiro and participants at seminars at the American Economic Association meetings 2006, Arizona State, UCLA, University of Minnesota, New York University, University of Michigan, Osaka University, SITE (Stanford), University of Texas, University of Tokoyo, and Yale. This work was supported by a grant from the Social Security Administration through the Michigan Retirement Research Center (Grant \# 10-P-98358-5). The opinions and conclusions are solely those of the authors and should not be considered as representing the opinions or policy of the Social Security Administration or any agency of the Federal Government. 


\section{Introduction}

Many of the proposed reforms of the US Social Security system that have recently received serious public airing do not focus on the potentially serious inefficiencies that the existing system creates. This paper takes a different course: it proposes and analyzes a reform that can address concerns about labor-supply distortions under the current program. The reform is simple and revenue neutral (for the Social Security system): after a long vesting period (say, 35-40 years of contributions), SSA would determine a worker's benefits using the current formula for all prospective retirement ages; after the vesting period, the worker would no longer face the Old Age Insurance payroll tax, and the worker's benefits would cease to vary with his or her actions. Individuals who continued to work after vesting would, in partial equilibrium, receive a 10.6 percent boost to their pay. Lost revenues to the system would be made up by a small increase in the payroll tax during the vesting period. Following the tradition of Auerbach and Kotlikoff [1987], we evaluate the effects of this reform with a standard life-cycle model. In contrast to the tradition, we estimate the parameters of our model using integrated micro data and a novel estimation strategy. The new strategy offers quite precise estimates of key parameters, allowing us to simulate the effects of the reform with considerable statistical confidence. We find that the proposed reform could have substantial effects on both behavior and welfare. Simulations indicate that retirement ages would rise by nearly a year on average and equivalent variations from the reform may average $\$ 5,000$ per household (1984 dollars) or more. When we account for welfare gains to society, which include additional income taxes from longer careers, this number increases to $\$ 7500$ per household.

The logic of our proposed reform emerges directly when the structure the current Social Security system is integrated with a life-cycle model (e.g., Diamond [1965], Tobin [1967], Auerbach and Kotlikoff [1987], Modigliani [1986], Hubbard et al. [1995], Altig et al. [2001], and many others) in which jobs require full-time work and the retirement decision is irreversible. Under the current system, for those with substantial earnings histories, the present value of Social Security benefits does not much depend on marginal earnings. Thus benefits are, for many, effectively lump sum and, given the low internal rate of return in the system, the tax-benefit structure generates an "income effect" that leads, on average, toward later retirement. We view this income effect, due to the legacy costs of the system, as unavoidable. The payroll tax also has, however, a substitution effect on labor supply. The tax lowers the marginal return to work, thereby tending to induce earlier retirement. In a model where the timing of retirement is the principal margin for labor supply, by doing away with the tax late in careers (but before optimal retirement), we eliminate the substitution effect and, therefore, the effective efficiency-threatening distortion of the Social Security system. 
To quantify the life-cycle effects of this reform, we develop a model with discrete, endogenous labor supply, where jobs require full-time work and retirement is permanent. The benefit to a household of later retirement is greater lifetime earnings; the cost is forgone leisure. As in Auerbach and Kotlikoff [1987], a household derives a flow of services from its consumption expenditure and leisure. The service flow, in turn, yields utility through a conventional isoelastic utility function. Although our "basic model" ignores health considerations, we present a second formulation with a stochastic, but insurable, chance of disability.

We estimate our life-cycle model's parameters using pseudo-panel consumption data from the Consumer Expenditure Survey (CEX) and lifetime earning and retirement data from the Health and Retirement Study (HRS). We pursue what we believe is a novel estimation strategy, first outlined in Laitner and Silverman [2005]. The model predicts a change in consumption expenditure at a household's retirement, due to the abrupt change in leisure and the intratemporal non-separability of consumption and leisure in the preference ordering. A number of recent empirical studies have described a drop in household consumption expenditure at the time of retirement (e.g., Banks et al. [1998], Bernheim et al. [2001], Hurd and Rohwedder [2003], Haider and Stephens [2004], Aguiar and Hurst [2004], and others). We use the magnitude of the drop, which this paper measures from CEX data, as well as age of retirement, which we measure from the HRS, to identify our key parameters.

Our analysis predicts that discontinuing the Social Security payroll tax after a vesting period of 34 years of contributions could lead households to postpone their retirement by nearly a year, on average. These results suggest that the social security system has important effects on the labor supply of older Americans. The analysis also suggests that the efficiency gains from our proposal are substantial. In particular, consumers, on average, would pay approximately $\$ 5,000$ in 1984 dollars for this reform. When we account for the social gain derived from income taxes on longer careers, this number increases to $\$ 7500$ per household. It is important to note that these gains do not, however, represent Pareto improvements - for some of those who, absent the reform, would have retired before the vesting age, the policy change results in a welfare loss.

Our plan is distinguished from many current proposals involving changes in the funding of the system or changes in the early or normal retirement ages in that it emphasizes efficiency over direct solvency concerns. ${ }^{1}$ The plan would not directly remedy current sol-

1 Similar reforms have been proposed elsewhere, both in an earlier version of this paper (ASSA annual meeting [2006]), and in work by others (Shah et al. [2006], Burtless and Quinn [2002]). Our work is, as far as we know, the first to evaluate the effects of this reform with an estimated life-cycle model. 
vency problems of the Social Security System, but our proposed reforms could mitigate inefficiencies from tax distortions to private labor supply decisions. And, longer careers would contribute to the nation's income-tax base, could tend to raise GDP and GDP per capita, and could augment households' lifetime resources from earnings.

This paper joins a large literature aimed at evaluating the effects of social security systems on labor supply. See Feldstein and Liebman [2002] for a review. By applying an explicit life-cycle model we differ from much of this literature, which seeks reduced form estimates. Implementing a structural model allows us, most importantly, to evaluate the life cycle effects of both the existing social security system and counterfactual reforms on retirement and consumption. As noted above, this structural approach follows the tradition of Auerbach and Kotlikoff [1987], but we depart from that tradition in that we estimate the parameters of our model from an integrated set of micro data.

By estimating the parameters of a fully-specified model, our paper also joins a smaller literature that provides structural estimates of life-cycle models of retirement (see, for example, Gustman and Steinmeier [1986], Rust and Phelan [1997], Bound et al. [2005], Blau [2005], French [2005], and van der Klaauw and Wolpin [2005]). Our paper is distinguished from this literature by its emphasis on a novel reform and by its use of life cycle consumption data. Our paper also differs from much of the recent work on structural models of retirement in that it adopts a certainty equivalent framework. We abstract from the effects of uninsured uncertainty. This choice is motivated by an effort to build a rich but tractable model that permits analytic as well as numerical insights. In this respect our paper attempts to bridge structural econometric and policy-oriented literatures. We view this approach as a logical one for evaluating our specific reform.

The organization of this paper is as follows. Section 2 describes our basic model and its formulation with stochastic disability. Section 3 discusses our pseudo-panel data on consumption expenditure, our HRS data on lifetime earnings and retirement ages, and our parameter estimates. Section 4 qualitatively and quantitatively analyzes the Social Security reform outlined above. Section 5 concludes.

\section{Model}

This section presents our basic model. Then it elaborates the framework to include stochastic disability.

2.1 Basic Model. We have an overlapping generations model. This paper restricts its analysis to couples. A household begins when its male reaches age $S$. He marries at age $S_{0}$ and has children $k=1, \ldots, K$ at age $S_{k}$. Males die at age $T^{M}$; females at age $T^{F}$. Set $T \equiv \max \left\{T^{M}, T^{F}\right\}$. 
A key feature of our model is intratemporally nonseparable preferences. A household's current utility depends on its current service flow from market consumption and leisure (e.g., Auerbach and Kotlikoff [1987]). This paper assumes the service flow is a CobbDouglas function of household consumption, $c$, and leisure, $\ell$, per capita:

$$
f(c, \ell) \equiv[c]^{\alpha} \cdot[\ell]^{1-\alpha}, \quad \alpha \in(0,1) .
$$

For couples, the man and woman work full time until retirement and retire when the male is age $R$. We normalize $\ell=1$ post retirement; prior to retirement

$$
\ell=\bar{\ell} \in(0,1) .
$$

A household's utility flow is an isoelastic function of its service flow:

$$
\frac{[f(c, \ell)]^{\gamma}}{\gamma}, \quad \gamma<1
$$

This paper's treatment of life-cycle changes in family composition follows Tobin [1967]. For household $i$ at age $t$ define

$$
\chi^{S}(i, t) \equiv \begin{cases}1, & \text { if age }-t \text { household includes a spouse } \\ 0, & \text { otherwise. }\end{cases}
$$

If household $i$ at age $t$ has $K$ "kids" of ages 0-17 define

$$
\chi^{K}(i, t) \equiv K .
$$

The number of "equivalent adults" in the household when it is age $t$ is

$$
n_{i t} \equiv 1+\chi^{S}(i, t) \cdot \xi^{S}+\chi^{K}(i, t) \cdot \xi^{K},
$$

where $\xi^{S}$ and $\xi^{K}$ are positive parameters. Economies of scale in household operation and/or the public-good nature of household consumption might well leave $\xi^{S}<1$ and $\xi^{K}<1$. The utility flow of household $i$ at age $t$ is

$$
\begin{array}{ll}
u\left(c_{i t}\right)=\frac{1}{\gamma} \cdot n_{i t} \cdot\left[\frac{c_{i t}}{n_{i t}}\right]^{\alpha \cdot \gamma} \cdot[\bar{\ell}]^{(1-\alpha) \cdot \gamma}, & \text { for } t \in[S, R), \\
v\left(c_{i t}\right)=\frac{1}{\gamma} \cdot n_{i t} \cdot\left[\frac{c_{i t}}{n_{i t}}\right]^{\alpha \cdot \gamma}, & \text { for } t \in[R, T] .
\end{array}
$$


In other words, flow utility depends upon consumption per equivalent adult and leisure per adult, weighted by number of equivalent adults. In general, the Tobin specification implies that, absent subjective discounting, a non-zero interest rate, or change in leisure, $c_{i t} / c_{j t}=n_{i t} / n_{j t}$.

In the present paper, household $i$ solves the following life-cycle problem:

$$
\begin{gathered}
\max _{R_{i}, c_{i t}} \int_{S_{i}}^{R_{i}} e^{-\rho \cdot t} \cdot u\left(c_{i t}\right) d t+\varphi\left(a_{i, R_{i}}+B_{i}\left(R_{i}\right) \cdot e^{r \cdot R_{i}}, R_{i}\right) \\
\text { subject to: } \quad \dot{a}_{i t}=r \cdot a_{i t}+y_{i t}-c_{i t}, \\
a_{i S}=0,
\end{gathered}
$$

where $\rho$ is the subjective discount rate; the household's adult male supplies $e_{i t}^{M}$ "effective hours" in the labor market per hour of work time; the adult female supplies $e_{i t}^{F}$ "effective hours;" the wage rate per effective hour is $w$; the income-tax rate is $\tau$; the Social Security and Hospital Insurance tax rate is $\tau^{s s}$; household net worth is $a_{i t}$; and,

$$
y_{i t} \equiv \begin{cases}(1-\bar{\ell}) \cdot\left[e_{i t}^{M}+e_{i t}^{F}\right] \cdot w \cdot\left(1-\tau-\tau^{s s}\right), & \text { for } S_{i} \leq t<R_{i} \\ 0, & \text { otherwise }\end{cases}
$$

"Effective hours" change with age, reflecting an individual's cumulative experience and economywide technological progress. The function $\varphi($.$) is$

$$
\begin{gathered}
\varphi\left(A+B_{i}\left(R_{i}\right) \cdot e^{r \cdot R_{i}}, R_{i}\right) \equiv \max _{c_{i t}} \int_{R_{i}}^{T} e^{-\rho \cdot t} \cdot v\left(c_{i t}\right) d t \\
\text { subject to: } \quad \dot{a}_{i t}=r \cdot a_{i t}-c_{i t}, \\
a_{i R_{i}}=A+B_{i}\left(R_{i}\right) \cdot e^{r \cdot R_{i}} \quad \text { and } \quad a_{i T} \geq 0,
\end{gathered}
$$

where the age- 0 present value of capitalized Social Security, Medicare, and private definedbenefit pension benefits is $B_{i}\left(R_{i}\right)$. A household takes $r, w, \tau, \tau^{s s}, e_{i t}^{M}, e_{i t}^{F}$, and $B($.$) as$ given. Social Security benefits only begin at age $\max \left\{R_{i}, 62\right\}$; Medicare benefits begin at age 65. Social Security and private-pension benefits depend upon retirement age. Social Security benefits are taxed at rate $\tau / 2$, private-pension benefits at rate $\tau$, and Medicare benefits are not taxed.

Although the criteria and asset constraints of (3)-(4) are only piecewise continuously differentiable, conventional optimality conditions remain valid provided costate variables have a continuous time paths — see Lemma 1 in the appendix. 
Our empirical analysis rests on two features of solutions to (3)-(4). The sign and magnitude of changes in $c_{i t}$ at retirement are the first - recall the introduction to this paper. We have

Proposition 1: Let household $i$ choose to retire at age $R=R_{i}$. Suppose that discontinuities in $n_{i t}$ and labor supply at retirement make the criterion and right-hand side of the asset equation discontinuous at monotone increasing ages $t_{j}, j=1, \ldots, J$. Let $t_{0} \equiv S=S_{i}$ and $t_{J+1} \equiv T$. Then a solution of (3)-(4) has

$$
\begin{gathered}
\frac{\dot{c}_{i t}}{c_{i t}}=\frac{r-\rho}{1-\alpha \cdot \gamma}, \\
c_{i t+}=M_{i j} \cdot c_{i t-}, \quad M_{i j} \equiv \frac{n_{i t+}}{n_{i t-}}, \quad t=t_{j}, j=1, \ldots, J, \quad \text { but } t \neq R, \\
c_{i R+}=M_{i j} \cdot c_{i R-}, \quad M_{i j} \equiv[\bar{\ell}]^{-\frac{(1-\alpha) \cdot \gamma}{1-\alpha \cdot \gamma}}, \quad t=t_{j}=R .
\end{gathered}
$$

Letting $M_{i 0}=1$, initial household consumption is

$$
c_{i S}=\psi\left(i, R_{i}\right) \equiv \frac{\int_{S}^{R_{i}} e^{-r \cdot t} \cdot y_{i t} d t+e^{-r \cdot R_{i}} \cdot B_{i}\left(R_{i}\right)}{\sum_{j=0}^{J}\left[\prod_{k=0}^{j} M_{i k}\right] \cdot \int_{t_{j}}^{t_{j+1}} e^{-r \cdot t} \cdot e^{\frac{r-\rho}{1-\alpha \cdot \gamma} \cdot t} d t} .
$$

Proof: See Appendix.

The result of greatest interest here is (7), which implies, and characterizes, a discontinuous change in consumption at retirement. The intuition is as follows. Inputs to a bivariate neoclassical production function are complementary in the sense that more of one raises the other's marginal product. If $u($.$) were linear, a household would desire to raise$ its consumption at retirement to take advantage of this complementarity. If $u($.$) departs$ from linearity, a second, competing force arises: a household desires to "smooth" its service flow intertemporally -inducing it to want to decrease $c_{i t}$ upon the cessation of work to offset increases in leisure. Condition (7) shows that complementarity predominates for $\gamma \in(0,1)$, but proclivities to smooth service flows win out for $\gamma<0$.

The second foundation of our empirical analysis is households' choice of $R_{i}$. To develop intuition on the choice, we have

Proposition 2: Given a solution to (3)-(4), at $R=R_{i} \in\left(S_{i}, T\right)$ one has

$$
\begin{aligned}
& {\left[\alpha \cdot\left[n_{i R}\right]^{1-\alpha \cdot \gamma} \cdot\left[c_{i R-}\right]^{\alpha \cdot \gamma-1} \cdot[\bar{\ell}]^{(1-\alpha) \cdot \gamma}\right] \cdot\left[y_{i R-}-c_{i R-}+c_{i R+}+B_{i}^{\prime}(R) \cdot e^{r \cdot R}\right]=} \\
& \quad \frac{1}{\gamma} \cdot\left[n_{i R}\right]^{1-\alpha \cdot \gamma} \cdot\left[\left[c_{i R+}\right]^{\alpha \cdot \gamma}-\left[c_{i R-}\right]^{\alpha \cdot \gamma} \cdot\left[\bar{\ell}^{(1-\alpha) \cdot \gamma}\right] .\right.
\end{aligned}
$$




\section{Proof: See Appendix.}

The idea of (9) is as follows. The left-hand side registers the advantage of a marginal increase in retirement age $R: y_{i R}$ - measures additional earnings contingent upon postponing retirement; $c_{i R+}-c_{i R-}$ registers the fact that if desired consumption declines after retirement, earnings may stretch farther; and, $B_{i}^{\prime}(R) \cdot e^{r \cdot R}$ measures incremental pensionbenefit gains. The left side of (9) multiplies the sum of these dollar advantages by the marginal utility of consumption, converting to units of utility. The right-hand side of (9) captures the disadvantage of postponing retirement, namely, the difference - which is positive - between the flow of utility after and before retirement. ${ }^{2}$

A second interpretation is also interesting. Divide both sides of (9) by $\left[n_{i R}\right]^{1-\alpha \cdot \gamma}$. $\left[c_{i R-}\right]^{\alpha \cdot \gamma}$, and notice that $c_{i R+} / c_{i R-}$ is a constant. Then the left side depends only on

$$
\frac{y_{i R-}+B_{i}^{\prime}(R) \cdot e^{r \cdot R}}{c_{i R-}},
$$

while the right side is constant. If the left-hand part falls with age, retirement occurs when the two sides become equal. Reductions in the growth rates of earnings and pension accumulation in old age encourage retirement. Increases in consumption - provided the latter's growth rate from (5) is positive - do the same because higher consumption raises the value of leisure. (In fact, we might surmise that differences in households' lifetime earnings and pension-accumulation patterns tend to promote heterogeneity of retirement ages, whereas the common lifetime rate of increase in consumption (see (5)) promotes homogeneity.)

2.2 Discussion. Two especially important features of our model are discrete labor supply options and intratemporally non-separable preferences.

2 The right-hand side of $(9)$ is positive as follows. Using (7), the sign on the right-hand side is

$$
\begin{aligned}
& \operatorname{sgn}\left(\frac{1}{\gamma}\right) \cdot \operatorname{sgn}\left([\bar{\ell}]^{\frac{-(1-\alpha) \cdot \gamma \cdot \alpha \cdot \gamma}{1-\alpha \cdot \gamma}}-[\bar{\ell}]^{(1-\alpha) \cdot \gamma}\right) \cdot \operatorname{sgn}\left(\left[c_{i R-}\right]^{\alpha \cdot \gamma}\right)= \\
& \operatorname{sgn}\left(\frac{1}{\gamma}\right) \cdot \operatorname{sgn}\left(1-[\bar{\ell}]^{\frac{(1-\alpha) \cdot \gamma}{1-\alpha \cdot \gamma}}\right) \cdot \operatorname{sgn}\left([\bar{\ell}]^{\frac{-(1-\alpha) \cdot \gamma \cdot \alpha \cdot \gamma}{1-\alpha \cdot \gamma}}\right)= \\
& \operatorname{sgn}\left(\frac{1}{\gamma}\right) \cdot \operatorname{sgn}\left(1-[\bar{\ell}]^{\frac{(1-\alpha) \cdot \gamma}{1-\alpha \cdot \gamma}}\right) .
\end{aligned}
$$

Recall that $\bar{\ell} \in(0,1)$ and $\alpha \in(0,1)$. If $\gamma \in(0,1)$, the sign of both terms in the last product is positive. If $\gamma<0$, each is negative. 
In our framework, households must either work full time or retire. While in practice employers do offer part-time jobs, the rate of pay may be lower than that for full-time work, possibilities of advancement more limited, etc. ${ }^{3}$ As Rust and Phelan [1997] write,

The finding that most workers make discontinuous transitions from fulltime work to not working, and the finding that the majority of the relatively small number of 'gradual retirees' reduce their annual hours of work by taking on a sequence of lower wage partial retirement 'bridge jobs' rather than gradually reducing hours of work at their full-time pre-retirement 'career job' suggests the existence of explicit or implicit constraints on the individual's choice of hours of work. [p.786]

An indivisible work day seems consistent with the fact that U.S. data show little trend in male work hours or participation rates after 1940, except for a trend toward earlier retirement 1940-80 (e.g., Pencavel [1986], Blundell and MaCurdy [1999], and Burkhauser et al. [1999]).

Although intratemporal additivity is perhaps the most common specification for utility in the life-cycle literature, such a formulation leaves any routine drop in consumption at retirement unexplained. Our nonseparable specification is similar to a number of papers (e.g., Auerbach and Kotlikoff [1987], King et al. [1988], Hurd and Rohwedder [2003], and Cooley and Prescott [1995]). Auerbach and Kotlikoff employ a CES aggregator for service flows, assuming an elasticity of substitution for $f($.$) of 0.75$ in their "base case;" Cooley and Prescott [1995], for example, use the same functional forms as we do. Deviating from the Cobb-Douglas service-flow function would complicate (5) and (7), exacerbating the shortcomings of our consumption data. Lower substitution possibilities would, on the other hand, have potentially interesting implications for retirement patterns in the long run; hence, less restrictive specifications remain a topic for future research.

2.3 Disability. This section augments the basic model to include a stochastic chance of disability. This paper considers only the case with actuarially fair insurance, it assumes that exogenous factors cause disability, and it assumes that one's health status is objectively verifiable.

Assume that a household's health status is either "not disabled" or "disabled," and that a disabled household can never again work. Once a household becomes disabled, it remains disabled until it reaches its (previously) chosen retirement age $R$, at which point

3 Reasons for the wage penalty for part-time work include daily fixed costs of startup and shutdown, scheduling and coordination problems, employer concern for timely return on training investments, and the fixed-cost nature of some employee benefits (e.g., Hurd [1996]). 
we reclassify it as retired. Let $p(t)$ be the probability that a household becomes disabled at age $t$. Let $P(s)$ be the probability of becoming disabled after age $s$ :

$$
P(s) \equiv 1-\int_{S}^{s} p(t) d t=\int_{S}^{T} p(t) d t-\int_{S}^{s} p(t) d t=\int_{s}^{T} p(t) d t
$$

At age $t<R$, a nondisabled household purchasing term disability insurance during the interval $[t, t+d t)$ would pay an insurance premium with annual rate $p(t) \cdot X_{i t} / P(t)-$ in other words, it would pay total premiums $p(t) \cdot X_{i t} d t / P(t)$, to receive (current-dollar) lump-sum benefit $X_{i t}$ in the event of disability. Whether disabled or not, household $i$ receives capitalized sum $B_{i}\left(R_{i}\right) \cdot e^{r \cdot R_{i}}$, in current dollars, at its chosen retirement age $R_{i}$; thus, retirement benefits implicitly include a disability-insurance component in our framework, and disability insurance need only tide a household over until its retirement age.

Disabled households benefit from full-time leisure; presumably disability lowers their utility as well. Assume the latter implies an additively separable term in the flow utility function. Such a term does not affect household behavior; so, for simplicity, our analysis omits it.

Behavior after retirement is the same as before; hence, problem (4) remains as above. If household $i$ happens to become disabled at age $D=D_{i}<R_{i}=R$ and has insurance payout $X_{i D}$, its cumulative utility for ages $t \in[D, T]$ is

$$
\bar{\varphi}\left(A+X_{i D}, D, R\right) \equiv \max _{\bar{c}_{i t}} \int_{D}^{R} e^{-\rho \cdot t} \cdot v\left(\bar{c}_{i t}\right) d t+\varphi\left(\bar{a}_{i R-}+B_{i}(R) \cdot e^{r \cdot R}, R\right)
$$

$$
\begin{gathered}
\text { subject to: } \quad \dot{\bar{a}}_{i t}=r \cdot \bar{a}_{i t}-\bar{c}_{i t}, \\
\bar{a}_{i D+}=A+X_{i D}, \\
\bar{a}_{i R} \geq 0 .
\end{gathered}
$$

We are now ready to set out a household's complete life-cycle problem for the environment with disability. Continue to let $D=D_{i}$ and $R=R_{i}$. At its inception, household $i$ solves 


$$
\begin{gathered}
\max _{R, c_{i t}} \int_{S}^{R} p(D) \cdot\left[\int_{S}^{D} e^{-\rho \cdot t} \cdot u\left(c_{i t}\right) d t+\bar{\varphi}\left(a_{i D-}+X_{i D}, D, R\right)\right] d D+ \\
{\left[1-\int_{S}^{R} p(t) d t\right] \cdot\left[\int_{S}^{R} e^{-\rho \cdot t} \cdot u\left(c_{i t}\right) d t+\varphi\left(a_{i R+}+B_{i}(R) \cdot e^{r \cdot R}, R\right)\right]} \\
\text { subject to: } \dot{a}_{i t}=r \cdot a_{i t}+y_{i t}-c_{i t}-\frac{p(t) \cdot X_{i t}}{P(t)} \text { for } t \leq D, R, \\
a_{i S}=0 .
\end{gathered}
$$

The criterion's first term captures lifetime utility if the household becomes disabled at age $D<R$; the second component captures lifetime utility if the household reaches its chosen retirement age $R$ without first becoming disabled.

Looking at the first component of the first integral in (13), one has

$$
\begin{aligned}
& \int_{S}^{R} p(D) \cdot \int_{S}^{D} e^{-\rho \cdot t} \cdot u\left(c_{i t}\right) d t d D= \\
& \int_{S}^{R} \int_{t}^{R} p(D) \cdot e^{-\rho \cdot t} \cdot u\left(c_{i t}\right) d D d t= \\
& \int_{S}^{R}[P(t)-P(R)] \cdot e^{-\rho \cdot t} \cdot u\left(c_{i t}\right) d t
\end{aligned}
$$

where the middle step uses Fubini's theorem. This enables us to rewrite the criterion as

$$
\begin{aligned}
\int_{S}^{R} & {\left[P(t) \cdot e^{-\rho \cdot t} \cdot u\left(c_{i t}\right)+p(t) \cdot \bar{\varphi}\left(a_{i t-}+X_{i t}, t, R\right)\right] d t+} \\
& P(R) \cdot \varphi\left(a_{i R-}+B_{i}(R) \cdot e^{r \cdot R}, R\right)
\end{aligned}
$$

from which the new model's analog to Proposition 1 follows:

Proposition 3: Consider the model with disability. Let household $i$ choose to retire at age $R=R_{i}$. Suppose that discontinuities in $n_{i t}$ and labor supply at retirement or disability make the criterion and right-hand side of the asset equation discontinuous at ages $t_{j}$, $j=1, \ldots, J$. Let $t_{0} \equiv S=S_{i}$ and $t_{J+1} \equiv T$. If $D=D_{i} \geq R$, a solution of (12)-(13) has

$$
\frac{\dot{c}_{i t}}{c_{i t}}=\frac{r-\rho}{1-\alpha \cdot \gamma},
$$




$$
\begin{gathered}
c_{i t+}=\frac{n_{i t+}}{n_{i t-}} \cdot c_{i t-}, \quad t=t_{j}, \quad j=1, \ldots, J, \quad \text { but } \quad t \neq R, \\
c_{i R+}=[\bar{\ell}]^{-\frac{(1-\alpha) \cdot \gamma}{1-\alpha \cdot \gamma}} \cdot c_{i R-} .
\end{gathered}
$$

If the household becomes disabled at age $D<R$, we replace (16) with

$$
c_{i D+}=[\bar{\ell}]^{-\frac{(1-\alpha) \cdot \gamma}{1-\alpha \cdot \gamma}} \cdot c_{i D-} \quad \text { and } \quad c_{i R+}=c_{i R-} .
$$

Let $M_{i j}$ be the consumption jump from (15)-(17) at $t_{j}, j=1, \ldots, J$, and let $M_{i 0}=1$. Since one breakpoint occurs at age $\min \{D, R\}$, write $t_{j}=t_{j}(D)$ when $D<R$ and $t_{j}=t_{j}(R)$ otherwise. Then the initial consumption of household $i$ is

$$
\begin{aligned}
& c_{i S}= \bar{\psi}(i, R) \equiv \\
& \frac{\int_{S}^{R} p(D) \cdot\left[\int_{S}^{D} e^{-r \cdot t} \cdot y_{i t} d t\right] d D+P(R) \cdot \int_{S}^{R} e^{-r \cdot t} \cdot y_{i t} d t+e^{-r \cdot R} \cdot B_{i}(R)}{D E N}, \\
& D E N \equiv \int_{S}^{R} p(D) \cdot\left[\sum_{j=0}^{J}\left[\prod_{k=0}^{j} M_{i k}\right] \cdot \int_{t_{j}(D)}^{t_{j+1}(D)} e^{-r \cdot t} \cdot e^{\frac{r-\rho}{1-\alpha \cdot \gamma} \cdot t} d t\right] d D+ \\
& P(R) \cdot \sum_{j=0}^{J}\left[\prod_{k=0}^{j} M_{i k}\right] \cdot \int_{t_{j}(R)}^{t_{j+1}(R)} e^{-r \cdot t} \cdot e^{\frac{r-\rho}{1-\alpha \cdot \gamma} \cdot t} d t .
\end{aligned}
$$

Proof: See Appendix.

The new feature of Proposition 3 is the change in consumption upon pre-retirement disability, namely, condition (17). The intuition for (17) is as follows. Although the possibility of disability reduces lifetime resources (cf. (8) and (18)), households adopt full insurance. The need to pay insurance premiums causes lifetime consumption to be lower, but, with insurance, the actual onset of disability causes a household no further financial hardship. The latter fact implies that a household chooses the same consumption change after becoming disabled as at the arrival of its planned retirement age in other circumstances.

The analog to Proposition 2 provides a first-order condition for each household's utility-maximizing retirement age:

Proposition 4: Given a solution to (4) and (12)-(13), at $R=R_{i} \in(S, T)$ one has 


$$
\begin{aligned}
& {\left[\alpha \cdot\left[n_{i R}\right]^{1-\alpha \cdot \gamma} \cdot\left[c_{i R-}\right]^{\alpha \cdot \gamma-1} \cdot[\bar{\ell}]^{(1-\alpha) \cdot \gamma}\right] \cdot\left[y_{R-}-c_{i R-}+c_{i R+}+B_{i}^{\prime}(R) \cdot e^{r \cdot R}-\frac{p(R) \cdot X_{i R}}{P(R)}\right]=} \\
& \quad \frac{1}{\gamma} \cdot\left[n_{i R}\right]^{1-\alpha \cdot \gamma} \cdot\left[\left[c_{i R+}\right]^{\alpha \cdot \gamma}-\left[c_{i R-}\right]^{\alpha \cdot \gamma} \cdot[\bar{\ell}]^{(1-\alpha) \cdot \gamma}\right]
\end{aligned}
$$

when $R_{i} \leq D_{i}$. Furthermore,

$$
X_{i R}=y_{i R-}-c_{i R-}+c_{i R+} .
$$

Proof: See Appendix.

As in Proposition 2, (19) balances retirement-induced losses of wages and retirement benefits against utility gains from more leisure. What is new is that only earnings net of disability-insurance cost constitute an advantage for postponing retirement. ${ }^{4}$

2.4 Estimation equations. This section derives the two equations on which our estimation depends.

The first equation comes from Proposition 3. When household $i$ is age $s$, it has experienced a set of ages, say, $\kappa(s, i)$, with breakpoints from family composition changes and retirement or disability. Let the consumption-level adjustment factors corresponding to breakpoints be $M_{i k}$ as in Proposition 3. Then Proposition 3 shows that

$$
c_{i s}=\bar{\psi}\left(i, R_{i}\right) \cdot\left[\prod_{k \in \kappa(s, i)} M_{i k}\right] \cdot e^{\frac{r-\rho}{1-\alpha \cdot \gamma} \cdot(s-S)} .
$$

Let $D_{i}$ be the household's age of disability. Define

$$
\chi^{R D}(i, t) \equiv \begin{cases}1, & \text { if } t \geq \min \left\{R_{i}, D_{i}\right\} \\ 0, & \text { otherwise. }\end{cases}
$$

Noting that $\kappa(s, i) \subseteq \kappa(s+1, i)$, and using (1), we then have

$$
\begin{aligned}
& \ln \left(c_{i, s+1}\right)-\ln \left(c_{i, s}\right)=\frac{r-\rho}{1-\alpha \cdot \gamma}+\sum_{k \in \kappa(s+1, i)-\kappa(s, i)} \ln \left(M_{i k}\right) \approx \\
& \quad \frac{r-\rho}{1-\alpha \cdot \gamma}+\xi^{S} \cdot\left[\chi^{S}(i, s+1)-\chi^{S}(i, s)\right]+\xi^{K} \cdot\left[\chi^{K}(i, s+1)-\chi^{K}(i, s)\right]+ \\
& \frac{(1-\alpha) \cdot \gamma \cdot \ln (\bar{\ell})}{\alpha \cdot \gamma-1} \cdot\left[\chi^{R D}(i, s+1)-\chi^{R D}(i, s)\right],
\end{aligned}
$$

4 This does not imply that the possibility of disability necessarily leads to earlier retirement - the cost of insurance induces an income effect, operating through $c_{i R-}$ in (19). 
where the approximation comes from a first-order Taylor series.

Consumption is very difficult to measure in practice. Our consumption data, described below, provides a pseudo panel of average consumption, $\bar{c}_{s t}$, for households of age $s$ at time $t$. If $i$ indexes individual households and $\omega_{i s t}$ gives household weights,

$$
\bar{c}_{s t}=\sum_{i} \omega_{i s t} \cdot c_{i s t}
$$

Since the distribution of earnings in practice is roughly lognormal and our life-cycle preferences are homothetic, think of household consumption in each age-year cell as lognormally distributed: $\ln \left(c_{i s t}\right) \sim N\left(\mu_{s t}, \sigma_{s t}^{2}\right)$.

Then

$$
\begin{gathered}
\sum_{i} \omega_{i s t} \cdot \ln \left(c_{i s t}\right) \approx E\left[\ln \left(c_{i s t}\right)\right]=\mu_{s t}, \\
\ln \left(\sum_{i} \omega_{i s t} \cdot c_{i s t}\right) \approx \ln \left(E\left[c_{i s t}\right]\right)=\mu_{s t}+\frac{\sigma_{s t}^{2}}{2} .
\end{gathered}
$$

Assuming $\sigma_{s+1, t+1} \approx \sigma_{s t}$ and letting $v_{s t}$ register consumption measurement error, our first equation for estimation follows from (21) and the two preceding expressions:

$$
\begin{aligned}
& \ln \left(\bar{c}_{s+1, t+1}\right)-\ln \left(\bar{c}_{s t}\right)= \\
& \quad \frac{r-\rho}{1-\alpha \cdot \gamma}+\xi^{S} \cdot\left[\sum_{i} \omega_{i, s+1, t+1} \cdot \chi^{S}(i, s+1, t+1)-\sum_{j} \omega_{j s t} \cdot \chi^{S}(j, s, t)\right]+ \\
& \xi^{K} \cdot\left[\sum_{i} \omega_{i, s+1, t+1} \cdot \chi^{K}(i, s+1, t+1)-\sum_{j} \omega_{j s t} \cdot \chi^{K}(j, s, t)\right]+ \\
& \quad \frac{(1-\alpha) \cdot \gamma \cdot \ln (\bar{\ell})}{\alpha \cdot \gamma-1} \cdot\left[\sum_{i} \omega_{i, s+1, t+1} \cdot \chi^{R D}(i, s+1, t+1)-\sum_{j} \omega_{j s t} \cdot \chi^{R D}(j, s, t)\right]+ \\
& v_{s+1, t+1}-v_{s t} .
\end{aligned}
$$

Our second estimation equation comes from the retirement-age choices of individual households. Given the consumption path from Proposition 3, we maximize (12)-(13) with respect to $R_{i}$. We have HRS data, described below, on the lifetime earnings, retirement age, and demographics for individual households. Letting $R_{i}$ be the actual retirement age of household $i$ and $R_{i}^{*}$ be our model's prediction, we estimate

$$
R_{i}=R_{i}^{*}+\epsilon_{i}
$$


where $\epsilon_{i}$ captures measurement error in retirement age; household mistakes; factors independent of our model, such as a particular employer's wishes; etc. Proposition 4 makes no reference to second-order conditions; consequently, we generate $R_{i}^{*}$ from a global maximization algorithm described below.

\section{Data and Estimation}

As the introduction previewed, this paper estimates (22) from CEX data and (23) from the HRS. After discussing the data sources, this section presents our parameter estimates. 3.1 CEX Data. Our primary data source for estimating (22) is the U.S. Consumer Expenditure Survey (CEX). It provides comprehensive consumption data. The CEX obtains diary information on small purchases from one set of households; for a second set of households, it conducts quarterly interviews that catalog major purchases. The survey also collects demographic data and data on the value of the respondent's house. At any given time, the sample consists of approximately 5,000 (7,000 after 1999) households, which each remain in the survey for at most 5 quarters. The survey was conducted at multi-year intervals prior to 1984 , and annually thereafter. This paper uses the surveys for 1984-2001. ${ }^{5}$

Earlier drafts (Laitner and Silverman [2005]) of this work compared CEX annual consumption totals with the National Income and Product Accounts. Assuming that the NIPA numbers are accurate, that item-nonresponse and other measurement errors of the survey typically make CEX totals too low, and that the relative magnitude of survey errors does not systematically vary with age, for each year we scale CEX consumption categories, uniformly across ages, to match NIPA amounts. Appendix II lists our categories and describes in detail three additional adjustments concerning the treatment of housing services, health care, and personal business expenditures. This paper abstracts from the empirical difference between consumption and expenditure (e.g., Aguiar and Hurst [2004]) and, except in the case of housing, draws no distinction between consumer durable stocks and flows.

Deflating with the NIPA personal consumption deflator, and using survey weights, we derive an adjusted average consumption amount, our $\bar{c}_{s t}$, for each age $s$ and year $t$. Due to the construction of the CEX from separate interview and diary surveys, and annual aggregation from quarterly, rotating-sample data, we do not have consumption figures for individual households. We organize the CEX data so that a household's age is the age of the wife for a married couple (and the single household head in other cases).

5 The web site http://stats.bls.gov.gov/csxhome.htm presents aggregative tables, codebooks, etc., for the CEX. This paper uses raw CEX data from the ICPSR archive, and we gratefully acknowledge the assistance of the BLS in providing "stub files" of changing category definitions. 
The CEX provides information on whether the household is married. Although the CEX also reports number of children age $0-17$, we construct our own measure of children per household to gain more flexibility: using Census data on births per woman at age $s \in\{15, \ldots, 49\}$ in year $t \in\{1920, \ldots, 2001\}$, we simulate the number of children of each age for women of each age $1984, \ldots, 2001$.

CEX data on retirement is unsatisfactory because the CEX questionnaire only asks whether the respondent is "retired" when he or she had zero weeks of work in the prior twelve months; therefore, we turn to the March Current Population Survey (CPS) 19842001 for our $\chi_{s}\left(R_{i}\right)$ variable. ${ }^{6}$ We consider a CPS household retired if the head is over 50 years old and answers that he or she is out of the labor force at the time of the March survey for reasons other than unemployment or, in the case of a male, is not "unemployed" but reports under 30 hours per week of work. This paper focuses on male retirement because males were more attached to the labor force in the cohorts of our data and because our analysis abstracts from a detailed model of decision making within dual-earner households.

3.2 Retirement Data. The HRS is our data source for estimating equation (23), though we calibrate some parts of our life-cycle framework.

Consider the calibrations first. We assume a constant gross-of-income tax real interest rate of $5 \% / \mathrm{yr}^{7}$ We disregard government transfer payments other than Social Security. Our income tax rate $\tau$ comes from government spending on goods and services less indirect taxes (already removed from profits, and implicitly absent from wages and salaries below). Dividing by national income, the average over $1952-2003$ is $14.28 \% /$ year. $^{8}$

6 Indeed, the average median retirement age 1984-2001 in the CEX data is 64-65, whereas it is about 62 in the CPS.

7 Our real interest rate comes from a ratio of factor payments to capital over the market value of private net worth. For the numerator, NIPA Table 1.13 gives corporate business income, indirect taxes, and total labor compensation. The first less the other two is our measure of corporate profits; the ratio of profits to profits plus labor remuneration is "profits share." We multiply the latter times corporate, noncorporate, and nonprofitinstitution income less indirect taxes. We add household-sector income (NIPA Table 1.13) less indirect taxes and labor remumeration. Finally, we subtract personal business expenses (brokerage fees, etc. from NIPA Table 2.5.5, rows 61-64). The denominator is U.S. Flow of Funds household and non-profit institution net worth (Table B.100, row 19), less government liabilities (Table L106c, row 20). We average beginning and end of year figures. For 1952-2003, the average is .0504. For comparison, Auerbach and Kotlikoff [1987] use 6.7\%/year, Altig et al. [2001] 8.3\%/yr., Cooley and Prescott [1995] $7.2 \% / y r$. , and Gokhale et al. [2001] use post-tax rates of 4\%/yr. and 6\%/yr.

8 Auerbach and Kotlikoff [1987], for example, use 15\%/year. 
In the calculations below, the Social Security benefit formula, including the ceiling on taxable annual earnings, follows the history of the U.S. system. One-half of Social Security benefits are subject to the income tax.

Our theoretical model assumes that adults work 40 hours per week until retirement and 0 hours per week thereafter. With $16 \times 7$ waking hours per week, we set ${ }^{9}$

$$
\bar{\ell}=\frac{16 \times 7-40}{16 \times 7}=.6429 .
$$

Turning to the HRS data, we derive earnings profiles and retirement ages from the original HRS survey cohort, consisting of households in which the respondent was age 51-61 in 1992. A majority of participant households signed a permission waiver allowing the HRS to link to their Social Security Administration (SSA) earnings history. Each history runs 1951-1991; our HRS survey data covers 1992, 1994, 1996, 1998, 2000, and 2002. We restrict attention to once-married couples with both spouses alive in 1992, with the husband having linked SSA earnings and remaining in the labor force until at least age 51, and with the wife having linked SSA data or reporting no market work prior to 1992. Men and women must have 8-24 years of education. They become adults at the age equaling years of education plus 6, and we drop those reaching this age before 1951 . Men and women live independently until marriage. (We set our age of marriage at the minimum of the reported age and age at first birth.) We assume that men die at the close of age 74 and women at the close of 80 . We exclude couples with more than 10 years age difference. Omitting households with incomplete data leaves 1095 couples.

As stated, we assume that a household retires when its male adult does. The HRS twice asks if each adult is retired and when retirement took place. Prior to 1992, a male is retired if he reports that status on either question. After 1992, a male who reports being retired and works less than 1500 hours per year, or who works less than 1500 hours and never again more than 1500 hours per year, is "retired." We exclude households that pass our criterion for retirement in one survey wave but fail to do so in a subsequent wave, reducing our sample to 1032 .

For men, we estimate a so-called earnings dynamics model of earnings, dividing the total HRS sample into 4 education groups, and regressing log constant-dollar earnings on a quartic in age and dummy variables for time. The regression error has an individual effect as well as a random term. The data is right censored at the Social Security tax cap prior to 1980 ; at $\$ 125,000$ for earnings $125,000-250,000$, at $\$ 250,000$ for earnings 250,000 500,000 , and at $\$ 500,000$ for earnings 500,000+ for 1981-1991. Our likelihood function

9 See also Cooley and Prescott [1995] — who, on the basis of time-use studies, determine that households devote $1 / 3$ of waking hours to work. 
takes the censoring into account. Laitner and Silverman [2005] presents more details. After 1991, survey data is available every other year. As a protection against coding errors, we exclude survey earnings greater than twice, or less than half, the earnings dynamics equation prediction for the same age. This paper assesses late-in-life earnings as follows. Using quadratic programming, we fit a convex quadratic function to each male's available earnings figures from 1986 onward, constraining the function to match 1986 earnings and have a non-positive slope at the last available work age. We interpolate missing data and extrapolate prospective earnings through age 69. (Although in our model a household has zero earnings after its male retires, our global maximization algorithm for $R^{*}$ - see below - utilizes the extrapolated figures.)

Although we use similar steps for female earnings, there are several differences. A woman who never works remains in our sample. As stated above, we assume a woman retires when her spouse does. We extrapolate non-zero late-in-life earnings only for women who supply market hours in the survey in the last year that their husband works. We are much more concerned than for men that women might have part-time earnings. Prior to 1992, therefore, a woman's earnings are her SSA earnings unless the latter are censored, in which case we impute from our female earnings dynamics equations. The HRS provides information in 1996 on whether a woman had non-FICA earnings prior to 1992 (i.e., earnings not covered in the Social Security system). If a woman had non-FICA jobs and provided beginning and end dates, we impute her earnings from our earnings-dynamics regressions; if she provided only the span of non-FICA employment, we subtract nonFICA employment years 1980-91, which are evident from the data, and probabilistically impute remaining years using our earnings-dynamics regressions; if a woman had nonFICA employment but provided no information on when or how long, we drop the couple from the sample on the basis of incomplete data.

Since HRS earnings are net of employer benefits (including health insurance, pension contributions, and employer Social Security tax), we multiply household earnings for each year by the ratio of NIPA total compensation to NIPA wages and salaries.

We derive Social Security benefits after retirement from the statutory benefit formula for 2000. We also incorporate a stream of Medicare benefits after age 65, less participant SMI cost. To do this, for each adult 65 and older, we add to household resources Medicare benefits equaling the SMI annual premium for 2000 (i.e., \$546) multiplied by the ratio of HI and SMI total expenditures to SMI premiums for 2000 (i.e., 10.7282 less 1).

This paper considers two possible measures of disability. In a sequence of questions about work status, the HRS asks respondents whether they are disabled and, if so, the year of onset. Table 1, column 1, presents the cumulative (with HRS household weights) fraction of men who characterize themselves in this way as disabled and are retired. As stated above, 
our sample is limited to men who retire after age 50. In terms of Section 2, the cumulative probability corresponds to $1-P(t)$ for each age $t$. Column 2 considers a less stringent measure. In a sequence of questions about health status, the HRS queries respondents on whether they have any health problems that "limit their ability to perform work." Column 2 presents cumulative fractions of men who are retired and who characterize themselves as disabled or who say they have a work-limiting health condition.

\section{Table 1. Cumulative Probability of Male Disability: HRS Data 1992-2002}

\begin{tabular}{|c|c|c|c|c|c|}
\hline Age & $\begin{array}{c}\text { Retired and } \\
\text { Disabled }\end{array}$ & $\begin{array}{c}\text { Retired and } \\
\text { Disabled or } \\
\text { Work-Limitation }\end{array}$ & Age & $\begin{array}{c}\text { Retired and } \\
\text { Disabled }\end{array}$ & $\begin{array}{c}\text { Retired and } \\
\text { Disabled or } \\
\text { Work-Limitation }\end{array}$ \\
\hline 51 & .0008 & .0027 & 61 & .0743 & .1701 \\
\hline 52 & .0016 & .0036 & 62 & .0935 & .2334 \\
\hline 53 & .0106 & .0162 & 63 & .1164 & .3132 \\
\hline 54 & .0140 & .0235 & 64 & .1339 & .3604 \\
\hline 55 & .0198 & .0373 & 65 & .1532 & .4175 \\
\hline 56 & .0249 & .0511 & 66 & .1720 & .4726 \\
\hline 57 & .0326 & .0662 & 67 & .2032 & .5422 \\
\hline 58 & .0489 & .0907 & 68 & .2370 & .6004 \\
\hline 59 & .0545 & .1088 & 69 & .2969 & .6980 \\
\hline 60 & .0640 & .1355 & 70 & .3619 & .7829 \\
\hline
\end{tabular}

Source: see text.

Tables 2-3 present summary statistics on other aspects of our HRS sample. Table 2 calculates the present value at age 50 of after-tax lifetime earnings (1984 dollars) for men, $Y M 50$, and women, $Y F 50$. (In these figures, earnings end at retirement or the respondent's last survey wave.) We can see that in this cohort, females' earnings average only 20 percent of males'. Table 2 also computes the present value of household Social Security benefits at male age 50. Table 3 warns that many men do not reach retirement age in our sample.

3.3 Estimation. Our estimation uses a method of moments approach. Letting $\vec{\beta}$ be the vector of parameters to be estimated, rewrite (22)-(23) as

$$
\begin{gathered}
q_{s t}^{1}(\vec{\beta})=v_{s+1, t+1}-v_{s t}, \\
q_{i}^{2}(\vec{\beta})=\epsilon_{i} .
\end{gathered}
$$


Table 2. Statistics for HRS Sample

\begin{tabular}{|c|c|c|c|c|c|}
\hline Variable & Mean & Minimum & Median & Maximum & $\begin{array}{c}\text { Coef. } \\
\text { Var. }\end{array}$ \\
\hline $\begin{array}{c}\text { Age Male Last } \\
\text { Works in Sample }\end{array}$ & 61.3043 & 55 & 61 & 69 & .0533 \\
\hline $\begin{array}{c}\text { Age Diff. Couple: } \\
\text { Male Age - Female }\end{array}$ & 2.9729 & -8 & 3 & 10 & .9802 \\
\hline Male Age Marriage & 24.2921 & 14 & 23 & 56 & .1770 \\
\hline Children per Couple & 2.8165 & 0 & 3 & 10 & .5402 \\
\hline YM50 & $1,581,000$ & 508,000 & $1,417,000$ & $12,278,000$ & .5843 \\
\hline YF50 & 312,000 & 0 & 240,000 & $2,437,000$ & .9921 \\
\hline B50 & 94,000 & 54,000 & 93,000 & 144,000 & .1499 \\
\hline
\end{tabular}

Source: see text. HRS household weights. Note: ages integer variables this paper.

\begin{tabular}{|c|c|c|}
\hline \multicolumn{3}{|c|}{ Table 3. HRS Couples by Male Retirement Status } \\
\hline Category & $\begin{array}{c}\text { Stringent Definition } \\
\text { Disability }\end{array}$ & $\begin{array}{c}\text { Disability Includes } \\
\text { Work-Limitations }\end{array}$ \\
\hline Retired/not disabled & 636 & 443 \\
\hline Never retires in sample & 288 & 280 \\
\hline Retires after disability & 74 & 197 \\
\hline Dies prior to retirement & 34 & 33 \\
\hline Total sample & 1032 & 953 \\
\hline
\end{tabular}

Source: see text. (a) Omits non-respondents work-limitations question.

Assume that the $v_{s t}$ and $\epsilon_{i}$ random variables are iid and mean 0. Standard steps yield a matrix $A$ diagonalizing the covariance matrix for (24):

$$
q_{s t}^{1 *}(\vec{\beta}) \equiv A \cdot q_{s t}^{1}(\vec{\beta})=\Upsilon_{s t}
$$

with $\Upsilon_{s t}$ iid and mean 0 . Let

$$
\vec{\beta} \equiv\left(\alpha, \gamma, \rho, \xi^{S}, \xi^{K}, \sigma_{\Upsilon}, \sigma_{\epsilon}\right) .
$$

Our moment conditions for (26) $\operatorname{are}^{10}$

${ }^{10}$ Parenthetically, solving these moment conditions is equivalent to estimating the fol- 


$$
\sum_{s t} q_{s t}^{1 *}(\vec{\beta}) \cdot\left[A \cdot V_{j}^{1}(s t)\right]=0, \quad j=1, \ldots, 4
$$

where

$$
\begin{gathered}
V_{1}^{1}(s t)=1, \quad V_{2}^{1}(s t)=\sum_{i} \omega_{i, s+1, t+1} \cdot \chi^{S}(i, s+1, t+1)-\sum_{j} \omega_{j s t} \cdot \chi^{S}(j, s, t) \\
V_{3}^{1}(s t)=\sum_{i} \omega_{i, s+1, t+1} \cdot \chi^{K}(i, s+1, t+1)-\sum_{j} \omega_{j s t} \cdot \chi^{K}(j, s, t) \\
V_{4}^{1}(s t)=\sum_{i} \omega_{i, s+1, t+1} \cdot \chi^{R D}(i, s+1, t+1)-\sum_{j} \omega_{j s t} \cdot \chi^{R D}(j, s, t) .
\end{gathered}
$$

Our estimation of (28) also includes year dummy variables for 1984-1999 — see below.

Turning to $q_{i}^{2}(\vec{\beta})=R_{i}-R_{i}^{*}$, for each household $i$ we solve (12)-(13) for integer values $R \in\{51, \ldots, 69\}$, setting the path of each household's consumption as in Proposition 3 ; we fit a quadratic to lifetime utility at the integer with the highest utility and its two closest neighbors; and, we determine $R_{i}^{*}$ from the quadratic's peak. In comparison to Proposition 4, this procedure has the advantage of ensuring that sufficiency conditions hold.

To meet the censoring problems evident in Table 3 , and including males who die before stopping work, assume $\epsilon_{i} \sim N\left(0, \sigma_{\epsilon}^{2}\right)$ and, letting $\phi\left(., \sigma_{\epsilon}^{2}\right)$ be the normal density, define

$$
\begin{aligned}
& q_{i}^{2 *}(\vec{\beta}) \equiv E\left[\epsilon_{i} \mid \text { data }, \vec{\beta}\right]= \begin{cases}q_{i}^{2}(\vec{\beta}) & \text { if voluntarily retires in sample } \\
\frac{\int_{q_{i}^{2}(\vec{\beta})}^{\infty} e \cdot \phi\left(e, \sigma_{\epsilon}^{2}\right) d e}{\int_{q_{i}^{2}(\vec{\beta})}^{\infty} \phi\left(e, \sigma_{\epsilon}^{2}\right) d e} & \text { otherwise }\end{cases} \\
& q_{i}^{3 *}(\vec{\beta}) \equiv E\left[\left(\epsilon_{i}\right)^{2} \mid \text { data }, \vec{\beta}\right]= \begin{cases}{\left[q_{i}^{2}(\vec{\beta})\right]^{2}} & \text { if voluntarily retires in sample } \\
\frac{\int_{q_{i}^{2}(\vec{\beta})}^{\infty} e^{2} \cdot \phi\left(e, \sigma_{\epsilon}^{2}\right) d e}{\int_{q_{i}^{2}(\vec{\beta})}^{\infty} \phi\left(e, \sigma_{\epsilon}^{2}\right) d e} & \text { otherwise. }\end{cases}
\end{aligned}
$$

lowing vector of parameter composites from (26) with FGLS:

$$
\left(\frac{r-\rho}{1-\alpha \cdot \gamma}, \quad \xi^{S}, \quad \xi^{K}, \quad \frac{(1-\alpha) \cdot \gamma \cdot \ln (\bar{\ell})}{\alpha \cdot \gamma-1}\right) .
$$


Then our HRS moment conditions are

$$
\sum_{i} q_{i}^{2 *}(\vec{\beta}) \cdot 1=0 \quad \text { and } \quad \sum_{i} q_{i}^{3 *}(\vec{\beta}) \cdot 1=\sigma_{\epsilon}^{2}
$$

Table 4 presents our estimates. Columns 1-2 use (28)-(29), with different definitions of disability. We call this our basic model. We employ pseudo-panel CEX data for $\mathrm{s}=30, \ldots, 80$, $\mathrm{t}=1984, \ldots, 2001$; after differencing, this yields 850 observations. (Starting the CEX data at very youthful ages introduces a selection problem because college graduates, for example, only join the sample at age 22 . With initial age 20 , our estimates would change; for starting ages 25-35, they are stable.) HRS sample sizes are as in Table 3.

Parameter estimates are similar in columns 1-2 - though $\sigma$ seems noticeably larger in column 2, perhaps suggesting that the stringent definition of disability is more consistent with agents' actual retirement behavior.

Columns 3-4 consider a substitute for (29). Column 1's methodology has the advantages of satisfying second-order conditions and allowing measurement error for $R_{i}$; it has the liability of requiring extrapolations of households' earning profiles past actual retirement — see, for example, French [2005] — though, in fairness, such extrapolations are necessary for the policy simulations of Section 4 in any case. Column 3-4's alternative has the opposite strengths and weaknesses. Define a replacement $Q_{i}^{2}(\vec{\beta})$ for $q_{i}^{2 *}(\vec{\beta})$ from the left-hand side of marginal condition (19) minus the right-hand side, evaluating the difference at each household's actual retirement age $R_{i}$. Set $Q_{i}^{2}(\vec{\beta})=\eta_{i}$, and assume $\eta_{i} \sim N\left(0, \sigma_{\eta}^{2}\right)$. One can interpret $\eta_{i}$ as an idiosyncratic (across households), additive preference for leisure - i.e., substitute $v\left(c_{i t}\right)+\eta_{i}$ in $(2)$ for $v\left(c_{i t}\right)$. Proposition 4 shows that $Q_{i}^{2}(\vec{\beta})=0$ at the desired retirement age in the absence of such heterogeneity. Observations from households that never retire in sample, that die before retiring, or that retire with disabilities, provide upper bounds for $\eta_{i}$, which straightforwardly generate an analog $Q_{i}^{3}(\vec{\beta})$ to $q_{i}^{3 *}(\vec{\beta})$. Equation (28) remains as before.

Fortunately, Table 4 does not point to a difficult choice between columns 1-4; the parameter estimates are very similar. (Violations of second-order conditions do, nevertheless, arise for a number of cases in columns 3-4.)

As stated, columns 1-4 incorporate time dummies in (28). In fact, aggregative disturbances might affect households of different ages differently. Instead of using time dummies, therefore, columns 5-6 average consumption changes $\ln \left(\bar{c}_{s+t, t+1}\right)-\ln \left(\bar{c}_{s t}\right)$ all $t$ to attenuate the influence of such shocks. Because the number of consumption observations shrinks to 50 , the standard errors rise; however, the point estimates change only very modestly.

Table 4's estimates of $\gamma$ vary from -.65 to -1.07 ; the estimates of $\alpha$ vary from .33 to .40; the estimates of $\rho$ vary from 0.00 to 0.01 . These correspond to estimates of an 
Table 4. Estimated Coefficients Equations (28)-(29): ${ }^{a}$

Estimated Parameter (Std. Error/T Stat.)

\begin{tabular}{|c|c|c|c|c|}
\hline \multirow{2}{*}{ Par. $^{b}$} & \multicolumn{2}{|c|}{$\begin{array}{l}\text { Basic Model } \\
\text { (see text) }\end{array}$} & \multicolumn{2}{|c|}{$\begin{array}{l}\text { Alt. Estimation } \\
\text { Using Prop. } 4\end{array}$} \\
\hline & $\begin{array}{l}\text { Stringent Def. } \\
\text { Male Disability }\end{array}$ & $\begin{array}{l}\text { Broad Def. } \\
\text { Male Disability }\end{array}$ & $\begin{array}{l}\text { Stringent Def. } \\
\text { Male Disability }\end{array}$ & $\begin{array}{l}\text { Broad Def. } \\
\text { Male Disability }\end{array}$ \\
\hline$\alpha$ & $\begin{array}{c}0.3298 \\
(0.0051 / 64.3325)\end{array}$ & $\begin{array}{c}0.3641 \\
(0.0053 / 68.3170)\end{array}$ & $\begin{array}{c}0.3469 \\
(0.0054 / 63.8677) \\
\end{array}$ & $\begin{array}{c}0.4032 \\
(0.0076 / 53.1299) \\
\end{array}$ \\
\hline$\gamma$ & $\begin{array}{c}-0.8539 \\
(0.1836 /-4.6515)\end{array}$ & $\begin{array}{c}-0.9434 \\
(0.2122 /-4.4459)\end{array}$ & $\begin{array}{c}-.8963 \\
(0.1981 /-4.5252)\end{array}$ & $\begin{array}{c}-1.0717 \\
(0.2681 /-3.9978\end{array}$ \\
\hline$\rho$ & $\begin{array}{c}0.0079 \\
(0.0029 / 2.7201) \\
\end{array}$ & $\begin{array}{c}0.0062 \\
(0.0034 / 1.8403) \\
\end{array}$ & $\begin{array}{c}0.0071 \\
(0.0032 / 2.2582) \\
\end{array}$ & $\begin{array}{c}0.0038 \\
(0.0044 / 0.8752) \\
\end{array}$ \\
\hline$\xi^{S}$ & $\begin{array}{c}0.3979 \\
(0.0541 / 7.3486)\end{array}$ & $\begin{array}{c}0.3979 \\
(0.0541 / 7.3486) \\
\end{array}$ & $\begin{array}{c}0.3979 \\
(0.0541 / 7.3486)\end{array}$ & $\begin{array}{c}0.3979 \\
(0.0541 / 7.3486) \\
\end{array}$ \\
\hline$\xi^{C}$ & $\begin{array}{c}0.1469 \\
(0.0105 / 14.0131)\end{array}$ & $\begin{array}{c}0.1469 \\
(0.0105 / 14.0131)\end{array}$ & $\begin{array}{c}0.1469 \\
(0.0105 / 14.0131)\end{array}$ & $\begin{array}{c}0.1469 \\
(0.0105 / 14.0131)\end{array}$ \\
\hline$\sigma$ & $\begin{array}{c}5.8852 \\
(0.0174 / 337.8194) \\
\end{array}$ & $\begin{array}{c}6.5846 \\
(0.0092 / 719.4954)\end{array}$ & & \\
\hline$\sigma_{\eta}$ & & & $\begin{array}{c}0.0116 \\
(0.0076 / 1.5223) \\
\end{array}$ & $\begin{array}{c}0.0040 \\
(0.0042 / 0.9465) \\
\end{array}$ \\
\hline & \multicolumn{4}{|c|}{ Calculated Parameters: ${ }^{d}$} \\
\hline$\alpha \cdot \gamma$ & $\begin{array}{c}-0.2816 \\
(0.0603 /-4.6687)\end{array}$ & $\begin{array}{c}-0.3435 \\
(0.0426 / 17.4673)\end{array}$ & $\begin{array}{c}-0.3109 \\
(0.0689 /-4.5156)\end{array}$ & $\begin{array}{c}-0.4322 \\
(0.1112 /-3.8857)\end{array}$ \\
\hline$\frac{r-\rho}{1-\alpha \cdot \gamma}$ & $\begin{array}{c}0.0273 \\
(0.0013 / 21.5044)\end{array}$ & $\begin{array}{c}0.0273 \\
(0.0013 / 21.5044)\end{array}$ & $\begin{array}{c}0.0273 \\
(0.0013 / 21.5044)\end{array}$ & $\begin{array}{c}0.0273 \\
(0.0013 / 21.5044)\end{array}$ \\
\hline$\frac{(1-\alpha) \cdot \gamma \cdot \ln (\bar{\ell})}{\alpha \cdot \gamma-1}$ & $\begin{array}{c}-0.1973 \\
(0.0334 /-5.9147) \\
\end{array}$ & $\begin{array}{c}-0.1973 \\
(0.0334 /-5.9147)\end{array}$ & $\begin{array}{c}-0.1973 \\
(0.0334 /-5.9147)\end{array}$ & $\begin{array}{c}-0.1973 \\
(0.0334 /-5.9147)\end{array}$ \\
\hline \multicolumn{5}{|c|}{ Observations Eq. (28)/Eq. (29): ${ }^{e}$} \\
\hline & $850 / 1032$ & $850 / 953$ & $850 / 1032$ & $850 / 953$ \\
\hline
\end{tabular}

a. Year dummies $1984,1985, \ldots, 1999$ for eq. (28) not reported.

b. Note: column 1-4 estimates of $\xi^{S}, \xi^{C}$, and second and third "calculated parameters" identical because of exact identification - recall fn 13.

c. "Stringent case male disability" refers to table 2, column 1; "broad case" refers to table 2, column 2.

d. Standard error from so-called delta method first row below; from GLS on (28) next two rows (see fn 13).

e. For sample size changes, see text. 


\begin{tabular}{|c|c|c|}
\hline \multicolumn{3}{|c|}{$\begin{array}{c}\text { Table } 4 \text { (cont). Estimated Coefficients Equations (28)-(29): } \\
\text { Estimated Parameter (Std. Error/T Stat.) }\end{array}$} \\
\hline \multirow{2}{*}{ Par. $^{b}$} & \multicolumn{2}{|c|}{$\begin{array}{c}\text { Basic Model; Time-Aggregated } \\
\text { CEX Data }\end{array}$} \\
\hline & $\begin{array}{l}\text { Stringent Def. } \\
\text { Male Disability }\end{array}$ & $\begin{array}{l}\text { Broad Def. } \\
\text { Male Disability }\end{array}$ \\
\hline$\alpha$ & $\begin{array}{c}0.3282 \\
(0.0166 / 19.776)\end{array}$ & $\begin{array}{c}0.3642 \\
(0.0174 / 20.8473)\end{array}$ \\
\hline$\gamma$ & $\begin{array}{c}-0.6496 \\
(0.4962 /-1.3093)\end{array}$ & $\begin{array}{c}-0.7092 \\
(0.5603 /-1.2658)\end{array}$ \\
\hline$\rho$ & $\begin{array}{c}0.0121 \\
(0.0062 / 1.9622) \\
\end{array}$ & $\begin{array}{c}0.0110 \\
(0.0072 / 1.5370)\end{array}$ \\
\hline$\xi^{S}$ & $\begin{array}{c}0.4318 \\
(0.2261 / 1.9101)\end{array}$ & $\begin{array}{c}0.4318 \\
(0.2261 / 1.9101) \\
\end{array}$ \\
\hline$\xi^{C}$ & $\begin{array}{c}0.1298 \\
(0.0265 / 4.9030)\end{array}$ & $\begin{array}{c}0.1298 \\
(0.0265 / 4.9030)\end{array}$ \\
\hline$\sigma$ & $\begin{array}{c}5.9138 \\
(0.0403 / 146.9143) \\
\end{array}$ & $\begin{array}{c}6.5908 \\
(0.0120 / 549.4285)\end{array}$ \\
\hline & \multicolumn{2}{|c|}{ Calculated Parameters: ${ }^{d}$} \\
\hline$\alpha \cdot \gamma$ & $\begin{array}{c}-0.2132 \\
(0.1588 /-1.3421)\end{array}$ & $\begin{array}{c}-0.2570 \\
(0.1986 /-1.2940)\end{array}$ \\
\hline$\frac{r-\rho}{1-\alpha \cdot \gamma}$ & $\begin{array}{c}0.0253 \\
(0.0027 / 9.2428)\end{array}$ & $\begin{array}{c}0.0253 \\
(0.0027 / 9.2428)\end{array}$ \\
\hline$\frac{(1-\alpha) \cdot \gamma \cdot \ln (\bar{\ell})}{\alpha \cdot \gamma-1}$ & $\begin{array}{c}-0.1589 \\
(0.1023 /-1.5537) \\
\end{array}$ & $\begin{array}{c}-0.1589 \\
(0.1023 /-1.5537) \\
\end{array}$ \\
\hline \multicolumn{3}{|c|}{ Observations Eq. (28)/Eq. (29): ${ }^{e}$} \\
\hline & $50 / 1032$ & $50 / 953$ \\
\hline
\end{tabular}

a. Year dummies $1984,1985, \ldots, 1999$ for eq. (28) not reported.

b. Note: column 1-2 estimates of $\xi^{S}, \xi^{C}$, and second and third

"calculated parameters" identical because of exact identification

— recall fn 13.

c. "Stringent case male disability" refers to table 2, column 1;

"broad case" refers to table 2 , column 2.

d. Standard error from the so-called delta method first row below;

from GLS on (28) next two rows (see fn 13).

e. For sample size changes, see text. 
intertemporal elasticity of substitution for services, $1 /(1-\gamma)$, of 0.48 to 0.61 , and an IES for pre-retirement consumption itself, $1 /(1-\alpha \cdot \gamma)$, of 0.70 to 0.83 . All estimates of $\gamma, \alpha$, and $\alpha \cdot \gamma$ in columns 1-4 are statistically different from zero at the 5 percent significance level.

Our estimates of $\gamma, \alpha$, and $\rho$ are similar to a number of calibrations in the literature. For example, Auerbach and Kotlikoff's [1987] favorite calibration has $\gamma=-3$, $\alpha$ (roughly) $=.4$, and $\rho=.015$; Altig et al. [2001] use $\gamma=-3, \alpha$ (roughly) $=.5$, and $\rho=.004$; and, Cooley and Prescott [1995] set $\gamma=0, \alpha=.36$, and $\rho=.053$.

Our results may also be compared with estimates that have identified the IES from expected changes interest rates. Using aggregate consumption data Hall [1988], Cambell and Mankiw [1989], and Patterson and Pesaran [1992], for example, estimate the IES for consumption to be very nearly zero. Micro studies tend to estimate larger intertemporal elasticities. Banks et al. [1998], for instance, estimate the average IES for consumption to be approximately 0.5. In another example, Attanasio and Weber [1993] estimate an IES for consumption of approximately 0.75 from micro data. ${ }^{11}$ Although our calculations rely a very different source of variation to estimate the IES, Table 4's outcomes are similar to, if on the larger end of, those obtained in micro studies from the change in consumption growth with expected changes in interest rates.

Table 4's second "calculated parameter" provides an estimate of the average lifetime growth rate for households' per capita consumption (see Prop. 3) of 2.5-2.7\%/yr. This suggests that between, say, ages 25 and 62 , in the absence of retirement a household's consumption per equivalent adult rises by a factor of about 2.62. In Auerbach and Kotlikoff [1987] the corresponding factor is about 1.54; in Gokhale et al. [2001], it is 1.74; in Tobin [1967], it is 13.33. For an infinite-lived representative agent model (e.g., Cooley and Prescott [1995]), the growth rate of consumption in a steady-state equilibrium would, of course, match the growth rate of GDP.

Our estimate of $\xi^{S}$ suggests that the addition of a spouse raises household consumption by 39-44 percent. This agrees fairly closely with the U.S. Social Security System's award to retired households of 50 percent extra benefits for a spouse. It is consistent with substantial returns to scale for larger households. Many papers in the literature implicitly set $\xi^{S}=1.0$, and Table 2 suggests that such calibrations may be misleading.

Estimates of our third "calculated parameter" suggests a 16-20 percent drop in con-

11 Barsky et al. [1997] use hypothetical questions to estimate an IES distribution for their sample. They find an average IES of 0.2 , with less than $20 \%$ of respondents having an IES greater than 0.3. Others who have attempted to estimate a distribution of intertemporal elasticities of substitution find evidence that the IES is increasing with wealth (e.g., Blundell et al. [1994]). 
sumption at retirement. This is consistent with, though at the smaller end of, estimates in Bernheim et al. [2001], Banks et al. [1998], Hurd and Rohwedder [2003], and the retirement brochures cited in Laitner [2001].

Our estimate of $\xi^{C}$ suggests an increase in household consumption of 13-15 percent for each child age 0-22. Since two parents correspond to 1.4 "equivalent adults," a child adds about 20 percent as much as each parent. Mariger [1986] estimates that children consume 30 percent as much as adults; Attanasio and Browning [1995, p. 1122] suggest 58 percent; Gokhale et al. [2001] assume 40 percent; most of the analysis in Auerbach and Kotlikoff [1987] implicitly weights children at zero; Tobin [1967] assumes teens consume 80 percent as much as adults, and minor children 60 percent. Our estimate would be consistent with parents who spend a great deal on their children but reduce expenditures on themselves at the same time - perhaps vicariously enjoying their children's consumption.

\section{Social Security Reform}

This section investigates the consequences of Social Security reforms in which the OASI tax, and benefit adjustments based on new earnings, cease at a specific age or following a specific span of career years. Individuals who avoid disability could retire at any age; however, those who continue working after the Social Security vesting age/period would enjoy a 10.6 percent increase in their aftertax wage. (As with the present system, individuals could start collecting Social Security benefits at age 62 or later, with an actuarially fair adjustment for postponed receipt.)

Table 5 presents simulation outcomes for different reforms and different parameter estimates. The table compares behavior of our HRS couples under the existing Social Security System to the same sample if it had lived its life under the specified reform. Our analysis is not general equilibrium in nature - wages and interest rates are exogenous — nor does this section study transitions after reforms announced in a household's midlife. Because we want to examine prospective reforms in an environment that is revenue neutral from the standpoint of the Social Security System, each of the table's simulations introduces a constant adjustment to historical Social Security taxes that equates the sample-average present value (at age 50) of Social Security taxes less benefits before and after reform. ${ }^{12}$

In row 1 of Table 5, for example, under the reform, couples realize that their Social Security vesting ends at age 54. Subsequent to male (female) age 54, aftertax male (female) wages rise 10.6 percent. If we disregard disability-shock realizations, the reform lengthens careers by 1.08 years on average. In practice, the onset of disability (or death) can limit

12 As this is an aggregative condition, the present value calculation employs the grossof-tax real interest rate. 


\begin{tabular}{|c|c|c|c|c|c|}
\hline \multicolumn{6}{|c|}{$\begin{array}{l}\text { Table 5. Simulations with Vesting by Age or by Span of Career: } \\
\text { Estimated Parameters as in Table } 4 ; 1984 \text { Dollars (NIPA PCE Deflator) }\end{array}$} \\
\hline $\begin{array}{c}\text { Vesting } \\
\text { Age } \\
\text { or } \\
\text { Vesting } \\
\text { Span } \\
\text { (Years) } \\
\end{array}$ & $\begin{array}{c}\text { Average } \\
\text { Change } \\
\text { Actual } \\
\text { Career } \\
\text { Years }\end{array}$ & $\begin{array}{l}\text { Average } \\
\text { Change } \\
\text { Desired } \\
\text { Career } \\
\text { Years }\end{array}$ & $\begin{array}{c}\text { Average } \\
\text { Equivalent } \\
\text { Variation } \\
\text { (PV Age 50) }\end{array}$ & $\begin{array}{c}\text { Average } \\
\text { [Equivalent } \\
\text { Variation } \div \\
\text { Lifetime } \\
\text { Earnings] }\end{array}$ & $\begin{array}{c}\text { Average Per } \\
\text { Household } \\
\text { Additional } \\
\text { Income Tax } \\
\text { Revenue } \\
\text { (PV Age 50) }\end{array}$ \\
\hline Age & \multicolumn{5}{|c|}{ Stringent Definition Disability; Vesting by Age ${ }^{a}$} \\
\hline 54 & 0.9733 & 1.0832 & 6192.90 & 0.0030 & 2996.66 \\
\hline 58 & 0.7920 & 0.8904 & 4375.64 & 0.0022 & 2340.89 \\
\hline 62 & 0.4281 & 0.5174 & 2348.83 & 0.0012 & 1150.01 \\
\hline 66 & 0.1803 & 0.2336 & 904.43 & 0.0005 & 451.09 \\
\hline Age & \multicolumn{5}{|c|}{ Broad Definition Disability; Vesting by $\mathrm{Age}^{b}$} \\
\hline 54 & 0.9472 & 1.2661 & 7195.95 & 0.0036 & 2430.67 \\
\hline 58 & 0.7736 & 1.0834 & 5438.54 & 0.0028 & 1902.54 \\
\hline 62 & 0.4716 & 0.7231 & 3327.37 & 0.0018 & 1070.30 \\
\hline 66 & 0.2141 & 0.3412 & 1422.17 & 0.0008 & 469.59 \\
\hline Span & \multicolumn{5}{|c|}{ Stringent Definition Disability; Vesting by Career $\operatorname{Span}^{a}$} \\
\hline 34 & 0.8743 & $\overline{0.9702}$ & 5170.61 & 0.0026 & 2725.23 \\
\hline 38 & 0.7579 & 0.8543 & 4134.92 & 0.0023 & 2261.47 \\
\hline 42 & 0.5046 & 0.5886 & 2506.85 & 0.0015 & 1299.64 \\
\hline 46 & 0.2071 & 0.2578 & 933.02 & 0.0006 & 442.64 \\
\hline Span & \multicolumn{5}{|c|}{ Broad Definition Disability; Vesting by Career $\operatorname{Span}^{b}$} \\
\hline 34 & 0.8006 & 1.0521 & 5847.23 & 0.0030 & 2058.27 \\
\hline 38 & 0.7484 & 0.9974 & 4934.35 & 0.0028 & 1875.72 \\
\hline 42 & 0.5131 & 0.7286 & 3206.71 & 0.0019 & 1172.27 \\
\hline 46 & 0.2261 & 0.3608 & 1299.32 & 0.0009 & 449.21 \\
\hline
\end{tabular}

a. Average lifetime earnings (PV age 50) $\$ 1,888,477.73$. Cases 994. In contrast to Table 4, we eliminate households retiring before age 52 or after 68 - allowing our existing solution algorithm (see text) a minimum of two years of latitude for post-reform retirement-age changes.

b. 918 cases (see preceding note). Average lifetime earnings (PV age 50) $\$ 1,884,319.51$. 
one's ability to benefit. Taking that into account, the average actual change in career length according to the simulation is 0.97 years. If we ask households ex ante how much they would pay to participate in the reformed Social Security System, column 3 shows they would offer, on average, $\$ 6193$ (in 1984 dollars, present value at male age 50), which amounts to 0.3 percent of their aftertax earnings.

To understand Table 5's results, consider Proposition 4. As in the discussion of Table 4 , let $Q_{i}^{2}(R)$ equal the left-hand side of (19) minus the right-hand side. As in our basic formulations, assume homogeneity of tastes; hence, at desired retirement age $R_{i}^{*}$, we have $Q_{i}^{2}\left(R_{i}^{*}\right)=0$. If $Q_{i}^{2}(R)$ is positive (negative), household $i$ should retire later (earlier). Using (17) and (20), and dropping the subscript $i$ for convenience,

$$
\begin{aligned}
& \operatorname{sign}\left(Q^{2}(R)\right)=\operatorname{sign}\left(\left(\frac{y_{R-}}{c_{R-}}\right) \cdot\left(1-\frac{p(R)}{P(R)}\right)+\frac{B^{\prime}(R) \cdot e^{r \cdot R}}{c_{R-}}-\left[[\bar{\ell}]^{\frac{-(1-\alpha) \cdot \gamma}{1-\alpha \cdot \gamma}}-1\right] \cdot\left(1-\frac{p(R)}{P(R)}\right)-\right. \\
& \left.\frac{1}{\alpha \cdot \gamma} \cdot\left[1-[\bar{\ell}]^{\frac{\gamma \cdot(1-\alpha)}{1-\alpha \cdot \gamma}}\right] \cdot[\bar{\ell}]^{\frac{-(1-\alpha) \cdot \gamma \cdot \alpha \cdot \gamma}{1-\alpha \cdot \gamma}}\right) \cdot
\end{aligned}
$$

Assuming that $p(R) / P(R)$ changes slowly with $R$, one can, therefore, limit one's attention to

$$
\left(\frac{y_{R-}}{c_{R-}}\right) \cdot\left(1-\frac{p(R)}{P(R)}\right) \text { and } \quad \frac{B^{\prime}(R) \cdot e^{r \cdot R}}{c_{R-}} .
$$

Under the current Social Security System, with the stringent definition of disability, average retirement-age values for households in our sample who are not forced to retire early because of disability or death are $y_{R_{-}} \approx \$ 35000, c_{R-} \approx \$ 40000, p(R) / P(R) \approx 0.26$, and $B^{\prime}(R) \cdot e^{r \cdot R} \approx \$ 1125$. In other words, in terms of Social Security cumulative benefits, the advantage of working one more year is relatively small; thus, (30) shows that the major determinants of retirement, on average, seem to be forgone earnings relative to consumption together with the value of leisure.

Turning to the impact of a reform, say, full vesting at age 54, there are four types of household. (i) Some households are disabled. They are constrained. Following a reform to Social Security, they cannot work longer. (ii) For a typical unconstrained couple who would otherwise retire at $R>54$, subsequent to reform $y_{R-}$ rises about $\$ 3600$ and $B^{\prime}(R)$. $e^{r \cdot R}$ declines to 0 . Thus, Proposition 4 shows that such a couple should choose to work longer. Net of disability insurance, an extra year's work yields about $\$ 2700$. Table 4 shows consumption rises steadily with age. Each extra planned year's work raises lifetime resources and, hence, consumption, as well. With one additional year's work, the rise in the denominator of the right-hand term of (30) and the disappearance of the right-hand term would offset nearly all the gain in aftertax earnings from reform. In other words, we expect 
an increase in average career length of about one year. (iii) A couple who had previously chosen to retire before age 54 would have no incentive on the margin to work longer after reform. On the contrary, $y_{R-}$ for $R<54$ would fall from the (slight) increase in Social Security taxes prior to age 54. $c_{R}$ - would fall too as lifetime resources diminish from the tax increase. Nevertheless, because the Social Security benefit component of household resources remains fixed, the drop in consumption will be less in percentage terms than the drop in earnings. Thus, the left-hand term of (30) will fall, causing $R^{*}$ to fall (slightly). (iv) Some couples who chose to retire before age 54 in the absence of reform might make a non-marginal response to reform, choosing to work to age 54 and, in fact, beyond, to take advantage of the new tax break. Couples in this category could show labor supply increases of more, perhaps much more, than 1 year.

Chart 1 displays the simulated distribution of retirement-age changes for vesting at age 58. One can see evidence of behavior from all four groups.

Table 5 shows that later vesting leads to smaller labor supply increases on average. This is expected: if a reform vests later in life, groups (i) and (iii) expand. In fact, the changes are substantial.

Turning to equivalent variations, we must remember than revenue neutrality demands an increase in the Social Security tax following reform. For line 1 of Table 5, the requisite tax increase is about 0.5 percent. Some households in group (i) and all in group (iii) pay the higher tax over their entire work lives but receive no benefit from reform. So, their equivalent variation can be quite negative. Groups (ii) and (iv), in contrast, can show positive equivalent variations. To the extent that members of group (ii) originally choose to work beyond age 54, they achieve redistributive gains at the expense of group (iii). Efficiency gains, gathered through longer working lives, should add to the equivalent variations of groups (ii) and (iv). In our partial equilibrium framework, redistributive gains and losses should exactly cancel out. Table 5 shows that average gains are positive; hence, overall efficiency gains are indicated in every row. Chart 2 shows the distribution of gains in the case of row 2.

If one contemplates reforms with a later vesting age, group (iii) should expand in relative size. Thus, Table 5's decline with vesting age in the average equivalent variation is not surprising.

In sum, any of the variants of our proposed reform yield positive average equivalent variations. On the other hand, by no means do all couples benefit, and for some households ex post losses are quite large in magnitude.

There is another factor worth considering: if a reform increases years of work, income tax revenues will rise. The latter generates social gains - after all, households consume the services of government whether they work or not. Table 5's last column assesses 
Chart 1: Distribution of Change in Retirement Age after Reform: Vesting Age 58

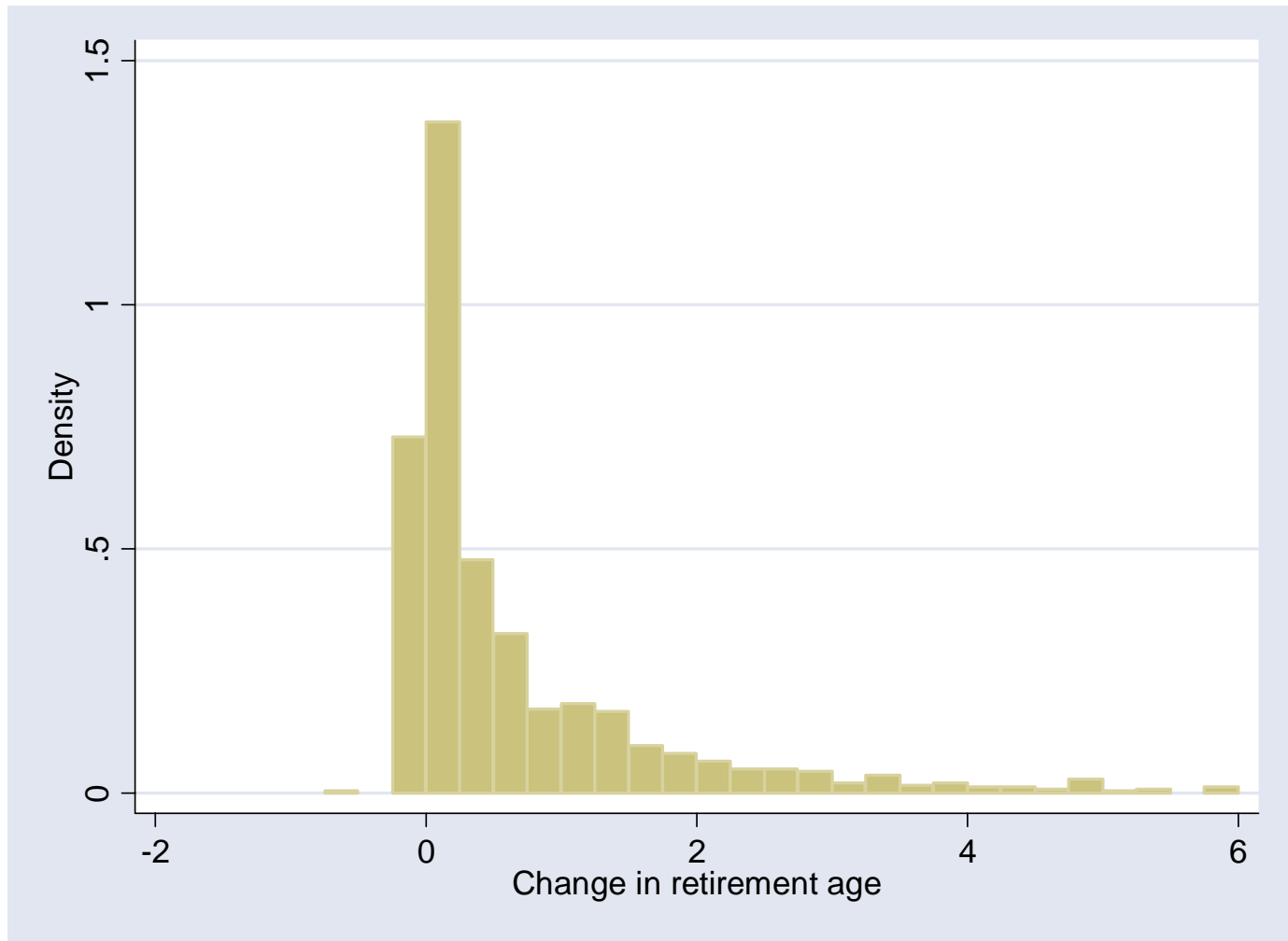

Chart 2: Distribution of Equivalent Variation of Reform: Vesting Age 58

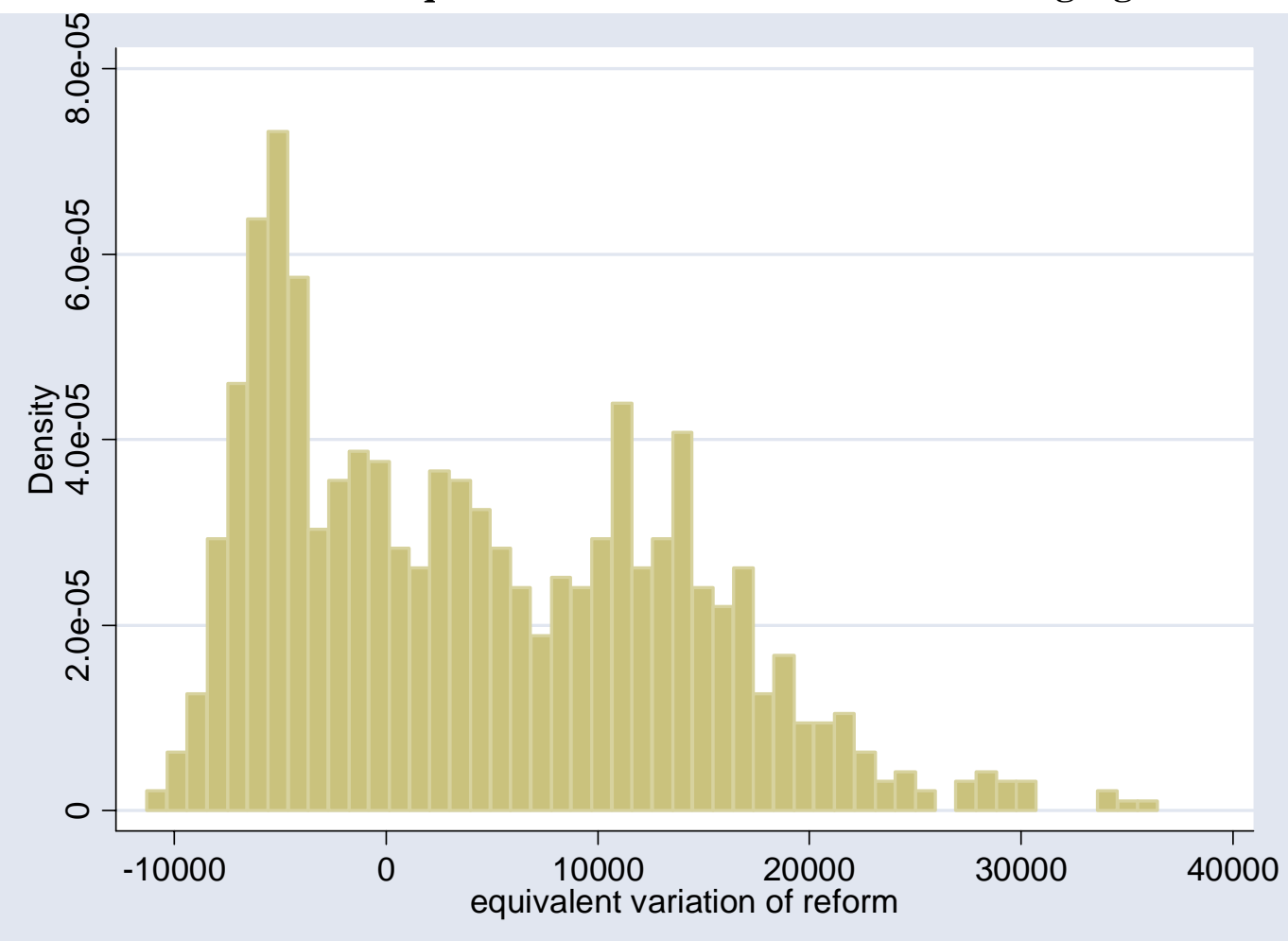


these social bonuses, measured on a per household basis exactly commensurate in units to column 3. The social gains augment column 3's personal gains by about 50 percent.

\section{Conclusion}

Recent proposals for U.S. Social Security reform have not addressed the potential inefficiencies that the system creates. This paper offers and analyzes an alternative, simple reform aimed at alleviating the labor-supply distortions of the current program. After a long vesting period (say, 35-40 years of contributions), the reformed policy would determine a worker's benefits using the current formula for all prospective retirement dates; but after the vesting period, the worker would no longer face the OASI payroll tax. For those who continued to work after vesting, wages would, in partial equilibrium, increase 10.6 percent. Lost revenues to the system would be made up by a small increase in the payroll tax during the vesting period. In a life-cycle model where the only margin of choice in labor supply is the timing of retirement, this reform eliminates the distortions of the Social Security system for those whose optimal retirement occurs after the vesting period.

We evaluate the effects of this reform in the context of a standard life-cycle model. In contrast to prominent work in this vein, we estimate the parameters of our model using integrated micro data and a novel estimation strategy. We find that the proposed reform could have substantial effects on both behavior and welfare. Simulations of the model indicate that retirement ages could rise by nearly a year on average, that a typical household might willingly pay as much as $\$ 6,000$ (1984 dollars) to participate in the reformed system, and that additional gains accruing to society from extra income taxes due to longer careers could average another $\$ 3000$ per household. The total gains are not, however, Pareto improvements: those who retire before the vesting period ends would transfer wealth to those who retire later.

The heterogeneity in its welfare consequences suggests that, while simple and seemingly plausible, the reform that this paper studies will not be unanimously embraced. Nevertheless, the magnitudes of the estimated increase in average retirement age and welfare suggest to us that the policy is worthy of further investigation. 


\section{Bibliography}

[1] Aguiar, Mark; and Erik Hurst "Consumption vs. Expenditure," NBER Working Paper 10307 (2004).

[2] Altig, David; Auerbach, Alan J.; Kotlikoff, Laurence J.; Smetters, Kent A.; and Walliser, Jan, "Simulating Fundamental Tax Reform in the United States," American Economic Review, vol. 91, no. 3 (June 2001): 574-59.

[3] Aizcorbe, Ana M.; Kennickell, Arthur B.; and Moore, Kevin B., "Recent Changes in U.S. Family Finances: Evidence from the 1998 and 2001 Survey of Consumer Finances," Federal Reserve Bulletin, vol. 89 (January 2003).

[4] Attanasio, Orazio, and Guglielmo Weber, "Consumption Growth, The Interest Rate and Aggregation," Review of Economic Studies 60, (1993): 631-649.

[5] Auerbach, Alan J.; and Kotlikoff, Laurence J. Dynamic Fiscal Policy. Cambridge: Cambridge University Press, 1987.

[6] Banks, James; Blundell, Richard; and Tanner, Sarah, "Is There a Retirement-Savings Puzzle?" American Economic Review 88, no. 4 (September 1998): 769-78.

[7] Barsky, Robert; Kimball, Miles; Juster, F. Thomas; and Shapiro, Matthew, "Preference Parameters and Behavioral Heterogeneity: An Experimental Approach in the Health and Retirement Study," Quarterly Journal of Economics vol. 112, no. 2 (May 1997): 537-79.

[8] Bernheim, B. Douglas; Skinner, Jonathan; and Weinberg, Steven, "What Accounts for the Variation in Retirement Wealth Among U.S. Households," American Economic Review 91, no. 4 (September 2001): 832-57.

[9] Blundell, Richard; Browning, Martin; and Meghir, Costas, "Consumer Demand and the Life-cyle Allocation of Expenditure," Review of Economic Studies (January 1994): $57-80$.

[10] Blundell, Richard; and MaCurdy, Thomas, "Labor Supply: A Review of Alternative Approaches," in Orley Ashenfelter and David Card (eds.), Handbook of Labor Economics: vol. 3A. Amsterdam: Elsevier, 1999.

[11] Burkhauser, Richard V.; Dwyer, Debra; Lindeboom, Maarten; Theeuwes, Jules; and Woittiez, Isolde, "Health, Work, and Economic Well-Being of Older Workers, Aged Fifty-One to Sixty-one: A Cross-National Comparison Using the U.S. HRS and the Netherlands CERRA Data Sets," in James Smith and Robert Willis (eds.), Wealth, Work, and Health: Innovations in Measurement in the Social Sciences. Ann Arbor: The University of Michigan Press, 1999.

[12] Burtless, Gary; and Quinn, Joseph, "Is Working Longer the Answer for An Aging Workforce?" Center for Retirement Research at Boston College Issue In Brief no. 11, December 2002. 
[13] Campbell, John; and Mankiw, N. Gregory, "Consumption, Income and Interest Rates: Reinterpreting the Time Series Evidence," NBER Macroeconomics Annual MIT Press (1989): 185-216.

[14] Cooley, Thomas; and Prescott, Edward "Economic Grwoth and Business Cycles" in Thomas Cooley (ed.), Frontiers of Business Cycle Research. Princeton, N.J., Princeton University Press (1995): 1-38.

[15] Diamond, P.A., "National Debt in a Neoclassical Growth Model," American Economic Review, vol. 55, no. 5 (December 1965): 1126-1150.

[16] French, E., "The Effects of Health, Wealth, and Wages on Labour Supply and Retirement Behavior," Review of Economic Studies 72(2) (April 2005): 395-427.

[17] Gokhale, Jagadeesh; Kotlikoff, Laurence J.; Sefton, James; and Weale, Martin, "Simulating the Transmission of Wealth Inequality via Bequests," Journal of Public Economics vol. 79, no. 1 (January 2001): 93-128.

[18] Gustman, Alan L.; and Steinmeier, Thomas L., "A Structural Retirement Model," Econometrica vol. 54, no. 3 (May 1986): 555-84.

[19] Gustman, Alan L., Mitchell, Olivia S., Samwick, Andrew A., and Steinmeier, Thomas L., "Evaluating Pension Entitlements," in Olivia Mitchell, P. Brett Hammond, and Anna M. Rappaport (ed.), Forecasting Retirement Needs and Retirement Wealth. Philadelphia: University of Pennsylvania Press, 2000.

[20] Haider, Steven; and Stephens, Melvin, Jr., "Is There a Retirement-Consumption Puzzle? Evidence Using Subjective Retirement Expectations," NBER Working Paper 10257, (2004).

[21] Hall, Robert E., "Intertemporal Substitution in Consumption," Journal of Political Economy 96, no. 2 (1988): 339-357.

[22] Hubbard, R. Glen; and Judd, Kenneth, "Liquidity Constraints, Fiscal Policy and Consumption," Brookings Papers on Economic Activity 1 (1986): 1-50.

[23] Hubbard, R. Glen; Skinner, Jonathan; and Zeldes, Stephen P., "Precautionary Saving and Social Insurance," Journal of Political Economy 103, no. 2 (April 1995): 360-99.

[24] Hurd, Michael, "The Effect of Labor Market Rigidities on the Labor Force Behavior of Older Workers," in (David Wise ed.), Advances in the Economics of Aging. Chicago: The University of Chicago Press, 1996.

[25] Hurd, Michael; and Rohwedder, Susann, "The Retirement-Consumption Puzzle: Anticipated and Actual Declines in Spending at Retirement," NBER working paper 9586 (2003), http://www.nber.org/papers/w9586.

[26] Ippolito, Richard A., Pension Plans and Employee Performance. Chicago: The University of Chicago Press, 1997.

[27] Jones, Larry E.; Manuelli, Rodolfo; Siu, Henry; and Stachetti, Ennio "Fluctuations 
in Convex Models of Endogenous Growth I: Growth Effects," mimeo, University of Minnesota (November 2003).

[28] Keane, Michael; and Wolpin, Kenneth, "The Effect of Parental Transfers and Borrowing Constraints on Educational Attainment," International Economic Review 42, No. 4 (November 2001): 1051-1103.

[29] King, Robert; Plosser, Charles; and Rebelo, Sergio, "Production, Growth and Business Cycles: I. The Basic Neoclassical Model," Journal of Monetary Economics vol. 21, no. 2 (1988): 195-232.

[30] Laitner, John, "Secular Changes in Wealth Inequality and Inheritance," The Economic Journal, vol. 111, no. 474 (October 2001): 691-721.

[31] Lucas, Robert E., Jr., "Supply Side Economics: An Analytical Review," Oxford Economic Papers vol. 42 (April 1990): 293-316.

[32] Lucas, Robert E., Jr., "Macroeconomic Priorities," The American Economic Review vol. 93. no. 1 (March 2003): 1-14.

[33] Mariger, Randall P. Consumption Behavior and the Effects of Government Fiscal Policy. Cambridge: Harvard University Press, 1986.

[34] Meghir, Costas; and Weber, Guglielmo, "Intertemporal non-separability or Borrowing Restrictions? A Disaggregate Analysis Using a US Consumption Panel," Econometrica vol. 64, no. 5 (September 1996): 1151-1181.

[35] Modigliani, Franco, "Life Cycle, Individiual Thrift, and the Wealth of Nations," American Economic Review 76, no. 3 (June 1986): 297-313.

[36] Paterson, Kerry D.; and Pesaran, Bahram, "The Intertemporal Elasticity of Substitution in Consumption in the U.S. and in the U.K.," Review of Economics and Statistics 74, no. 4 (May 1992): 573-84.

[37] Pencavel, John, "Labor Supply of Men: A Survey," in Orley Ashenfelter and David Card (eds.), Handbook of Labor Economics: vol. 1. Amsterdam: Elsevier, 1986.

[38] Rust, John; and, Phelan, Christopher., "How Social Security and Medicare Affect Retirement Behavior in a World of Incomplete Markets," Econometrica 65, no. 4 (July 1997): 781-831.

[39] Shah, Gopi Goda; Shoven, John; and Slavov, Sita. "REmoving the Disincentives for Long Careers in Social Security." Occidental College working paper, 2006.

[40] Stock, James H.; and, Wise, David A., "Pensions, The Option Value of Work, and Retirement," Econometrica 58, no. 2 (September 1990): 1151-1180.

[41] Tobin, J., "Life Cycle Saving and Balanced Growth," in W. Fellner (ed.), Ten Economic Studies in the Tradition of Irving Fisher. New York: Wiley, 1967.

[42] Weil, Philippe, "The Equity Premium Puzzle and the Risk-Free Rate Puzzle," Journal of Monetary Economics, vol. 24, no. 3 (November 1989): 401-21. 
[43] Yogo, Motohiro, "Estimating the Elasticity of Intertemporal Substitution When Instruments Are Weak," Review of Economics and Statistics, vol. 86, no. 3, (August 2004): $797-810$.

[44] Zeldes, S., "Consumption and Liquidity Constraints: An Empirical Investigation," Journal of Political Economy 97, no. 4 (April 1989): 305-46. 


\section{Appendix I: Proofs}

Lemma 1: Suppose that discontinuities in $n_{i t}$ and labor supply at retirement make criterion (3)-(4) and right-hand side of the asset equation discontinuous at ages $t_{j}$. Define a present-value Hamiltonian with costate variable $\lambda$ :

$$
\mathcal{H} \equiv\left\{\begin{array}{ll}
e^{-\rho \cdot t} \cdot u\left(c_{i t}\right)+\lambda_{i t} \cdot\left[r \cdot a_{i t}+y_{i t}-c_{i t}\right], & \text { for } t \in\left[S, R_{i}\right), \\
e^{-\rho \cdot t} \cdot v\left(c_{i t}\right)+\lambda_{i t} \cdot\left[r \cdot a_{i t}-c_{i t}\right], & \text { for } t \in\left[R_{i}, T\right] .
\end{array} .\right.
$$

Then for a given $R_{i}$, the following conditions are necessary and sufficient for an optimum:

$$
\begin{gathered}
\frac{\partial \mathcal{H}}{\partial c}=0 \quad \text { all } t, \\
\dot{\lambda}_{i t}=-\frac{\partial \mathcal{H}}{\partial a} \quad \text { all } t, \\
\dot{a}_{i t}=r \cdot a_{i t}+y_{i t}-c_{i t} \quad \text { all } t \neq R_{i}, \\
a_{i S}=0, \quad a_{i R_{i}+}=a_{i R_{i}-}+B_{i}\left(R_{i}\right) \cdot e^{r \cdot R_{i}}, \quad \text { and } a_{i T}=0 .
\end{gathered}
$$

Proof of Lemma 1: Let $R_{i}$ be given. Begin with problem (4). Suppose it has one breakpoint, $t_{1} \in\left(R_{i}, T\right)$. Solving the subproblem for $t \geq t_{1}$ - which is standard — we have (i)-(iv). Call the subproblem's maximized criterion $\Phi\left(a_{i t_{1}}, t_{1}\right)$. Next, solve

$$
\max _{c_{i t}} \int_{R_{i}}^{t_{1}} e^{-\rho \cdot t} \cdot u\left(c_{i t}, i, t, R_{i}\right) d t+\Phi\left(a_{i t_{1}}, t_{1}\right)
$$

with the same constraints as (4). This is a standard problem: we have (i)-(iii) and

$$
\lambda_{i t_{1}-}=\frac{\partial \Phi\left(a_{i t_{1}}, t_{1}\right)}{\partial a} .
$$

(See, for example, Kamien and Schwartz [1981].) Since $a_{i t}$ is continuous by nature, it only remains to show that $\lambda_{i t}$ is continuous at $t_{1}$. But, the envelope theorem shows

$$
\frac{\partial \Phi\left(a_{i t_{1}}, t_{1}\right)}{\partial a}=\lambda_{i t_{1}+}
$$

Combining (v)-(vi) establishes continuity of the costate at $t_{1}$. Induction on the number of breakpoints, say, $J^{\prime}$, in (4) establishes continuity for any $J^{\prime}$. The logic of (v)-(vi), with $\Phi()=.\varphi($.$) , establishes continuity of the costate at t=R_{i}$. The same arguments apply for $t<R_{i}$. 
Proof of Proposition 1: Suppose we have a solution of (3)-(4). Fix the $R_{i}$. The optimal consumption path must solve (3)-(4) conditional on this $R_{i}$. Follow Lemma 1. From (ii), $\dot{\lambda}_{i t}=-r \cdot \lambda_{i t}$. Then for $t \in\left(t_{j}, t_{j+1}\right)$, we have

$$
\begin{array}{lr}
e^{-\rho \cdot t} \cdot\left[n_{i t}\right]^{1-\alpha \cdot \gamma} \cdot\left[c_{i t}\right]^{\alpha \cdot \gamma-1} \cdot\left[\ell_{i t}\right]^{(1-\alpha) \cdot \gamma}=\lambda_{i t} & \text { from Lemma 1, (i) } \\
\Longleftrightarrow(\alpha \cdot \gamma-1) \cdot \frac{\dot{c}_{i t}}{c_{i t}}=\rho-r, & \text { since } t \in\left(t_{j}, t_{j+1}\right)
\end{array}
$$

establishing (5). For $t=t_{j}, j=1, \ldots, J$, Lemma 1 shows $\lambda_{i t}$ is continuous; so,

$$
\begin{aligned}
& e^{-\rho \cdot t} \cdot\left[n_{i t-}\right]^{1-\alpha \cdot \gamma} \cdot\left[c_{i t-}\right]^{\alpha \cdot \gamma-1} \cdot\left[\ell_{i t}\right]^{(1-\alpha) \cdot \gamma}=\lambda_{i t}= \\
& e^{-\rho \cdot t} \cdot\left[n_{i t+}\right]^{1-\alpha \cdot \gamma} \cdot\left[c_{i t+}\right]^{\alpha \cdot \gamma-1} \cdot\left[\ell_{i t}\right]^{(1-\alpha) \cdot \gamma}, \quad \text { from Lemma 1, (i) }
\end{aligned}
$$

establishing (6). For $t=R_{i}$, by the same logic, since $\ell_{i t+}=1$,

$$
\begin{array}{cl}
e^{-\rho \cdot t} \cdot\left[n_{i t}\right]^{1-\alpha \cdot \gamma} \cdot\left[c_{i t-}\right]^{\alpha \cdot \gamma-1} \cdot\left[\ell_{i t-}\right]^{(1-\alpha) \cdot \gamma}=\lambda_{i t}= & \\
e^{-\rho \cdot t} \cdot\left[n_{i t}\right]^{1-\alpha \cdot \gamma} \cdot\left[c_{i t+}\right]^{\alpha \cdot \gamma-1}, \quad \text { from Lemma 1, (i) }
\end{array}
$$

establishing (7). Integrating budget constraint (iii) from $t=S$ to $T$ gives (8).

Proof of Proposition 2: For any $R=R_{i}$, define a Hamiltonian as in Lemma 1. It can serve for both (3) and (4). Lemma 1 shows

$$
\lambda_{i R}=\frac{\partial \varphi\left(a_{i R}+B_{i}(R) \cdot e^{r \cdot R}, R\right)}{\partial a} .
$$

Using (vii) and Kamien and Schwartz [1981],

$$
\begin{aligned}
& \frac{\partial \varphi\left(a_{i R}+B_{i}(R) \cdot e^{r \cdot R}, R\right)}{\partial R}= \\
& \quad \lambda_{i R} \cdot\left[B_{i}^{\prime}(R) \cdot e^{r \cdot R}+r \cdot B_{i}(R) \cdot e^{r \cdot R}\right]-\mathcal{H}\left(c_{i R+}, a_{i R+}, \lambda_{i R}, R\right) .
\end{aligned}
$$

As household $i$ chooses $R=R_{i}$ in (3), we have a "free endpoint problem." Kamien and Schwartz show that the necessary condition for an optimal $R \in(S, T)$ is

$$
\mathcal{H}\left(c_{i R-}, a_{i R-}, \lambda_{i R}, R\right)+\frac{\partial \varphi\left(a_{i R}+B_{i}(R) \cdot e^{r \cdot R}, R\right)}{\partial R}=0 .
$$


Hence, for an optimal $R \in(S, T)$, (viii)-(ix) imply

$$
\begin{aligned}
& e^{-\rho \cdot R} \cdot u\left(c_{i R}\right)+\lambda_{i R} \cdot\left[r \cdot a_{i R-}+y_{R-}-c_{i R-}\right]+ \\
& \quad \lambda_{i R} \cdot\left[B_{i}^{\prime}(R) \cdot e^{r \cdot R}+r \cdot B_{i}(R) \cdot e^{r \cdot R}\right]- \\
& e^{-\rho \cdot R} \cdot v\left(c_{i R}\right)-\lambda_{i R-} \cdot\left[r \cdot a_{i R+}-c_{i R+}\right]=0 .
\end{aligned}
$$

Recall that $a_{i R+}=a_{i R-}+B_{i}(R) \cdot e^{r \cdot R}$. Hence, the preceding simplifies to

$$
\begin{array}{r}
e^{-\rho \cdot R} \cdot u\left(c_{i R}\right)+\lambda_{i R} \cdot\left[y_{R-}-c_{i R-}+c_{i R+}\right]+ \\
\lambda_{i R} \cdot\left[B_{i}^{\prime}(R) \cdot e^{r \cdot R}\right]-e^{-\rho \cdot R} \cdot v\left(c_{i R}\right)=0 .
\end{array}
$$

As (i), Lemma 1, shows that

$$
\lambda_{i t}=e^{-\rho \cdot t} \cdot \frac{\partial u\left(c_{i t}\right)}{\partial c} \quad \text { for } \quad t<R,
$$

condition (x) establishes (9).

Proof of Proposition 3: Fix $R=R_{i}$ for the remainder of this proof. Set up Hamiltonians for, respectively, disability problem (12), retirement problem (4), and lifetime problem with possible disability (13):

$$
\begin{gathered}
\mathcal{D} \equiv e^{-\rho \cdot t} \cdot v\left(\bar{c}_{i t}\right)=\bar{\Lambda}_{i t} \cdot\left[r \cdot \bar{a}_{i t}-\bar{c}_{i t}\right], \quad t \geq D, \\
\mathcal{R} \equiv e^{-\rho \cdot t} \cdot v\left(c_{i t}\right)+\Lambda_{i t} \cdot\left[r \cdot a_{i t}-c_{i t}\right], \quad t \geq R, \\
\mathcal{H} \equiv P(t) \cdot e^{-\rho \cdot t} \cdot u\left(c_{i t}\right)+p(t) \cdot \bar{\varphi}\left(a_{i t-}+X_{i t}, t, R\right)+ \\
\lambda_{i t} \cdot\left[r \cdot a_{i t}+y_{i t}-c_{i t}-\frac{p(t) \cdot X_{i t}}{P(t)}\right], \quad t<R .
\end{gathered}
$$

The costate variables are $\bar{\Lambda}_{i t}, \Lambda_{i t}$, and $\lambda_{i t}$, respectively.

Step 1. At demographic breakpoints, the analysis follows the proof of Proposition 1 exactly.

Step 2. We have

$$
\frac{\partial \mathcal{R}}{\partial c_{i R}}=0 \Rightarrow e^{\rho \cdot R} \cdot \frac{\partial v\left(c_{i R}\right)}{\partial c}=\Lambda_{i R},
$$




$$
\begin{array}{cc}
\Lambda_{i R}=\frac{\partial \varphi\left(a_{i R}+B_{i}(R) \cdot e^{r \cdot R}, R\right)}{\partial a_{i R}}, & \text { envelope theorem } \\
\lambda_{i R}=P(R) \cdot \frac{\partial \varphi\left(a_{i R}+B_{i}(R) \cdot e^{r \cdot R}, R\right)}{\partial a_{i R}}, & \text { F.O.C. for (13) } \\
\frac{\partial \mathcal{H}}{\partial c}=0 \Rightarrow P(R) \cdot e^{-\rho \cdot R} \cdot \frac{\partial u\left(c_{i R}\right)}{\partial c}=\lambda_{i R} . & \text { F.O.C. for (13) }
\end{array}
$$

These four equations together establish (16).

Step 3. We have

$$
\begin{array}{cc}
\frac{\partial \mathcal{H}}{\partial X_{i D}}=0 \Rightarrow p(D) \cdot \frac{\partial \bar{\varphi}\left(a_{i D-}+X_{i D}, D, R\right)}{X_{i D}}=\lambda_{i D} \cdot \frac{p(D)}{P(D)} & \\
\Rightarrow P(D) \cdot \frac{\partial \bar{\varphi}\left(a_{i D-}+X_{i D}, D, R\right)}{X_{i D}}=\lambda_{i D}, & \text { F.O.C. for (13) } \\
\frac{\partial \mathcal{H}}{\partial c_{i D}}=0 \Rightarrow P(D) \cdot e^{-\rho \cdot D} \cdot \frac{\partial u\left(c_{i D}\right)}{c_{i D}}=\lambda_{i D}, & \text { F.O.C. for (13) } \\
\frac{\partial \mathcal{D}}{\partial \bar{c}_{i D}}=0 \Rightarrow e^{-\rho \cdot D} \cdot \frac{\partial v\left(\bar{c}_{i D}\right)}{c_{i D}}=\bar{\Lambda}_{i D}, & \text { F.O.C. for (12) } \\
\frac{\partial \bar{\varphi}\left(a_{i D-}+X_{i D}, D, R\right)}{X_{i D}}=\bar{\Lambda}_{i D} . &
\end{array}
$$

These four equations together establish (17).

Step 4. The numerator of (18) is the expected present value of the household's lifetime earnings and retirement benefits. (One could subtract disability-insurance premiums and add expected disability-insurance benefits, but they would exactly balance.) The denominator times $c_{i S}$ is the expected present value of lifetime consumption. 
Proof of Proposition 4: Use the notation from the proof of Proposition 3. Analogous to the proof of Proposition 2, we have

$$
\begin{gathered}
\mathcal{H}\left(c_{i R}, a_{i R}, \lambda_{i R}, R\right)+\frac{\partial\left[P(R) \cdot \varphi\left(a_{i R}+B_{i}(R) \cdot e^{r \cdot R}, R\right)\right]}{\partial R}=0 \\
\Longleftrightarrow \mathcal{H}(.)+P(R) \cdot \frac{\partial \varphi(.)}{R}-p(R) \cdot \varphi(.)=0, \\
\frac{\partial \varphi\left(a_{i R}+B_{i}(R) \cdot e^{r \cdot R}, R\right)}{\partial R}= \\
\Lambda_{i R} \cdot\left[B_{i}^{\prime}(R) \cdot e^{r \cdot R}+r \cdot B_{i}(R) \cdot e^{r \cdot R}\right]-\mathcal{R}\left(c_{i R}, a_{i R}+B_{i}(R) \cdot e^{r \cdot R}, \lambda_{i R}, R\right) .
\end{gathered}
$$

Combining (xi)-(xii),

$$
\begin{aligned}
P & (R) \cdot e^{-\rho \cdot R} \cdot u\left(c_{i R}\right)+p(R) \cdot \bar{\varphi}\left(a_{i R}+X_{i R}, R\right)+\lambda_{i R} \cdot\left[r \cdot a_{i R-}+y_{i R}-c_{i R-}-\frac{p(R) \cdot X_{i R}}{P(R)}\right]+ \\
& P(R) \cdot \Lambda_{i R} \cdot\left[B_{i}^{\prime}(R) \cdot e^{r \cdot R}+r \cdot B_{i}(R) \cdot e^{r \cdot R}\right]- \\
& P(R) \cdot\left[e^{-\rho \cdot R} \cdot v\left(c_{i R}\right)+\Lambda_{i R} \cdot\left[r \cdot a_{i R-}+r \cdot B_{i}(R) \cdot e^{r \cdot R}-c_{i R+}\right]\right]- \\
& p(R) \cdot \varphi\left(a_{i R-}+B_{i}(R) \cdot e^{r \cdot R}, R\right)=0 .
\end{aligned}
$$

The proof of Proposition 3 shows

$$
\lambda_{i R}=P(R) \cdot \Lambda_{i R} .
$$

By construction,

$$
\bar{\varphi}\left(a_{i R-}+X_{i R}, R\right)=\varphi\left(a_{i R-}+B_{i}(R) \cdot e^{r \cdot R}, R\right) .
$$

First-order conditions for (13) imply

$$
P(R) \cdot e^{-\rho \cdot R} \cdot u^{\prime}\left(c_{i R}\right)=\lambda_{i R} .
$$

So, (xiii) simplifies to

$$
\begin{aligned}
& P(R) \cdot e^{-\rho \cdot R} \cdot u^{\prime}\left(c_{i R}\right) \cdot\left[y_{i R-}-c_{i R-}+c_{i R+}-\frac{p(R) \cdot X_{i R}}{P(R)}+B_{i}^{\prime}(R) \cdot e^{r \cdot R}\right]= \\
& \quad P(R) \cdot e^{-\rho \cdot R} \cdot\left[v\left(c_{i R+}\right)-u\left(c_{i R-}\right)\right],
\end{aligned}
$$


which establishes (19).

Proposition 3 shows that term disability insurance for $[t, t+d t)$, where the interval ends with retirement, should cover lost earnings, corrected for changing consumption needs in the disabled state; hence,

$$
\frac{p(R)}{P(R)} \cdot X_{i R} d t=\frac{p(R)}{P(R)} \cdot\left[y_{i R-}-c_{i R-}+c_{i R+}\right] d t
$$

This completes the proof.

\section{Appendix II: Adjustments of the CEX Data}

We divide the NIPA and CEX data into 11 categories: food, apparel, personal care, shelter, household operation, transportation, medical care, recreation, education, personal business, and miscellaneous. Detailed adjustments include the following.

(1) We subdivide "shelter" into "services from own house" and "other." We scale the latter as we do other categories, but we drop the CEX "services from own house" and impute a substitute that allocates the annual NIPA total service flow from residential houses to the CEX in proportion to CEX reported house values.

(2) CEX medical expenditures omit employer contributions to health insurance and services that Medicare covers. We annually, proportionately, and for every age adjust CEX expenditures on private health insurance to match the Department of Health and Human Services total for all premiums for private health insurance; and, we adjust out-of-pocket health spending from the CEX to match annual DHHS totals. ${ }^{13}$ Turning to Medicare, funding for the benefits comes from a hospital insurance (HI) tax on wages and salaries, monthly premiums for supplementary medical insurance (SMI) from people currently eligible for benefits, and contributions from general tax revenues to SMI. The CEX registers only SMI premiums from participants; so, we allocate the yearly total of Medicare benefits (both HI and all SMI expenditure) to the CEX sample in proportion to SMI premium payments (principally for people over 65$).{ }^{14}$

(3) The NIPA "personal business" category includes bank and brokerage fees, many of which are hidden in the form of low interest on saving accounts, etc., and hence absent from expenditures which CEX households perceive. We assume that bank and brokerage fees make their way into the life-cycle model in the form of lower-than-otherwise interest

13 See http://www.cms.hhs.gov/statistics/burden-of-health-care-costs/table01.asp. The annual figures cover 1987-2000. We extrapolate to 1984-86 and 2001 using the growth rate of NIPA total medical consumption.

14 For HI expenditures, see Social Security Bulletin, Annual Statistical Supplement 2001, table 8.A1; for SMI receipts and receipts from participant premiums, see table 8.A2. 
rates on saving; therefore, we normalize annual personal business expenditures measured in the CEX to match the corresponding NIPA amount less bank and brokerage fees, and omit bank and brokerage fees from our measure of consumption. 